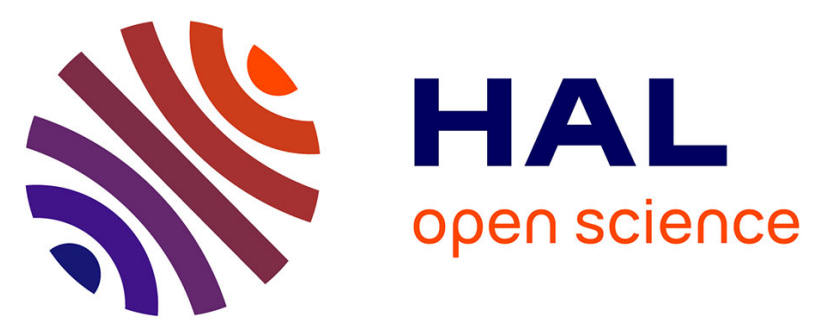

\title{
Layered Simple Hydroxides Functionalized by Fluorene-Phosphonic Acids: Synthesis, Interface Theoretical Insights, and Magnetoelectric Effect
}

Quentin Evrard, Ziyad Chaker, Mélissa Roger, Charlotte M. Sevrain, Emilie Delahaye, Mathieu Gallart, Pierre Gilliot, Cedric Leuvrey, Jean-Michel Rueff, Pierre Rabu, et al.

\section{To cite this version:}

Quentin Evrard, Ziyad Chaker, Mélissa Roger, Charlotte M. Sevrain, Emilie Delahaye, et al.. Layered Simple Hydroxides Functionalized by Fluorene-Phosphonic Acids: Synthesis, Interface Theoretical Insights, and Magnetoelectric Effect. Advanced Functional Materials, 2017, 27 (41), pp.1703576. 10.1002/adfm.201703576 . hal-01624542

\section{HAL Id: hal-01624542 \\ https://hal.univ-brest.fr/hal-01624542}

Submitted on 28 Jan 2022

HAL is a multi-disciplinary open access archive for the deposit and dissemination of scientific research documents, whether they are published or not. The documents may come from teaching and research institutions in France or abroad, or from public or private research centers.
L'archive ouverte pluridisciplinaire HAL, est destinée au dépôt et à la diffusion de documents scientifiques de niveau recherche, publiés ou non, émanant des établissements d'enseignement et de recherche français ou étrangers, des laboratoires publics ou privés. 


\title{
Article type: Full Paper
}

\section{Layered Simple Hydroxides functionalized by fluorene-phosphonic acids : synthesis, interface theoretical insights and magneto electric effect}

Quentin Evrard, ${ }^{\#}$ Ziyad Chaker, ${ }^{\#}$ Mélissa Roger, Charlotte M. Sevrain, Emilie Delahaye, Mathieu Gallart, Pierre Gilliot, Cédric Leuvrey, Jean-Michel Rueff, Pierre Rabu, Carlo Massobrio, Mauro Boero, Alain Pautrat, Paul-Alain Jaffrès, Guido Ori, * Guillaume Rogez*

Q. Evrard, Z. Chaker, Dr. E. Delahaye, Dr. M. Gallart, Dr. Pierre Gilliot, C. Leuvrey, Dr. P. Rabu, Dr. C. Massobrio, Dr. M. Boero, Dr. G. Ori, Dr. G. Rogez

Institut de Physique et Chimie des Matériaux de Strasbourg, Université de Strasbourg, CNRS UMR 7504, F-67034 STRASBOURG Cedex 2, France

E-mail: guido.ori@ipcms.unistra.fr; guillaume.rogez@ipcms.unistra.fr

Dr. M. Roger, Dr. C. M. Sevrain, Pr. P.-A. Jaffrès

CEMCA, CNRS UMR 6521, Université de Brest, IBSAM, 6 Avenue Victor Le Gorgeu, 29238 BREST, France

Dr. J.-M. Rueff, Dr. A. Pautrat

CRISMAT, CNRS UMR 6508, ENSICAEN

6 bd du Maréchal Juin, 14050 CAEN Cedex, France

Keywords: fluorene phosphonic acid, layered simple hydroxides, magneto-electric effect, first-principles molecular dynamics

\begin{abstract}
Copper- and cobalt-based layered simple hydroxides are successfully functionalized by a series of fluorene mono- and di-phosphonic acids, using anionic exchange reactions and a preintercalation strategy. The lateral functionalization of the fluorene moieties has only little impact on the overall structure of the obtained layered hybrid materials but it influences the organization of the molecules within the interlamellar spacing. For bulky fluorene (9,9-dioctyl derivative), luminescence is preserved when inserted into copper and cobalt hydroxydes, whereas it is completely quenched for the other fluorenes. Detailed characterization of the internal structure and chemical bonding properties for copper- and cobalt-based hybrids is performed via ancillary experimental techniques. For the copper-based LSH class, for which more elusive findings are found, first-principles molecular dynamics simulations unravel the fundamental stabilizing role of the H-bonding network promoted within the local environments of the fluorene mono- and di-phosphonic acids.
\end{abstract}


The cobalt series of compounds constitute a new class of hybrid magnets, with ordering temperatures ranging from $11.8 \mathrm{~K}$ to $17.8 \mathrm{~K}$ and show a clear magnetoelectric effect. This effect appears above a threshold magnetic field which is null below the magnetic ordering temperature, and it persists in the paramagnetic regime till about $110 \mathrm{~K}$.

\section{Introduction}

The field of multiferroic materials (ie materials in which at least two of electric, magnetic and elastic orders coexist) is currently mainly covered by oxides, but hybrid and moleculebased materials are recently emerging. ${ }^{[1,2]}$ Among molecule-based materials, one may quote coordination polymers and Metal-Organic Frameworks ${ }^{[3,4]}$ or the series of compounds $\left[\left(\mathrm{CH}_{3}\right)_{2} \mathrm{NH}_{2}\right]\left[\mathrm{M}(\mathrm{HCOO})_{3}\right]$ (with $\mathrm{M}=\mathrm{Mn}, \mathrm{Co}, \mathrm{Ni}, \mathrm{Fe}$ ) which illustrates the most studied achievements in the MOFs approach to multiferroics. ${ }^{[5,6]}$ The non-collinear magnetic ordering occurring below $\mathrm{T}_{\mathrm{N}}=8.5 \mathrm{~K}$ to $35.6 \mathrm{~K}$, depending on the transition metal ion, ${ }^{[7,8]}$ coexists with an antiferroelectric order which develops at higher temperature $(170 \mathrm{~K}) .{ }^{[5]}$ The central cation can also be modified to tune the properties and ordering temperatures. ${ }^{[9]}$ Moreover, it has been shown that some of these compounds could offer an electric control of the magnetization which should be very attractive for advanced memory devices. ${ }^{[10]}$

Another example of hybrid multiferroic compound has been obtained by taking advantage of the hosting behavior and magnetic properties of oxalate-bridged two-dimensional networks. ${ }^{[1]}$ This material is ferromagnetic below $T_{C}=3.9 \mathrm{~K}$ and ferroelectric in the whole temperature range. No magneto-electric coupling could be evidenced in this material.

Finally, the last family of multiferroic hybrid compounds is built on layered perovskites, which are excellent candidates because they combine structural flexibility with robust magnetic and electrical properties. ${ }^{[12-14]}$ The study of $\mathrm{CuCl}_{4}$-based hybrids, with ethyl ammonium or phenyl-ethyl ammonium counter ions, reveals that these systems present a coexistence of ferromagnetic ordering below $9 \mathrm{~K}$ and $13 \mathrm{~K}$ respectively, originating from the 
inorganic part, and improper ferroelectric ordering below $247 \mathrm{~K}$ and $340 \mathrm{~K}$ respectively, originating from the hydrogen-bond (H-bond) ordering of the organic part. ${ }^{[15,16]}$.

It therefore appears that the still scarcely explored chemical hybrid approach to multiferroics and magnetoelectrics may present various advantages with respect to the solid state chemistry approach, in terms of synthesis and possibility to modulate rather easily the structures and properties. Moreover, hybrid materials, where the two sub-networks responsible for the magnetic and electric properties are deeply interwoven, are a priori more likely to present magneto-electric coupling compared to nanostructured composite materials, the potential magneto-electric coupling being essentially tied to the interface. ${ }^{[17-19]}$

In this respect, layered insertion compounds are particularly worthy of interest. Many works about multifunctional hybrids concerned layered bimetallic trioxalatometalates, ${ }^{[20,21]}$ hexathiohypodiphosphates ${ }^{[22]}$ or magnetic layered double hydroxides, ${ }^{[23]}$ because they can be functionalized with various ligands via versatile reactions. Striking results were recently reported concerning combination of magnetism with chirality, ${ }^{[24]}$ ferroelectricity, ${ }^{[11]}$ superconductivity, ${ }^{[23]}$ or Non Linear Optics. ${ }^{[25]}$

Most of the preceding layered functional materials are characterized by weak bonds between sub-networks, which may limit synergy between properties. An alternative approach consists in the insertion and grafting of functional organic molecules into magnetic layered transitionmetal hydroxides $\mathrm{M}_{\mathrm{x}}(\mathrm{OH})_{2 \mathrm{x}-\mathrm{ny}}\left(\mathrm{X}^{\mathrm{n}-}\right)_{\mathrm{y}}\left(\mathrm{M}(\mathrm{II})=\mathrm{Co}\right.$ or $\mathrm{Cu}$ and $\mathrm{X}^{-}=$carboxylate, sulfate or sulfonate anion). The $\mathrm{X}^{\mathrm{n}-}$ anion located in the interlayer space may be substituted by a large variety of molecules via anionic exchange reaction. ${ }^{[26-31]}$ Whereas various organic molecules and coordination complexes bearing carboxylic or sulfonic acid anchoring functions have been successfully inserted into these Layered Simple Hydroxides (LSH), to the best of our knowledge, phosphonic acid anchoring groups have never been used in such systems. As for the related compounds Layered Double Hydroxides, $\left[\mathrm{M}_{1-\mathrm{x}}{ }^{2+} \mathrm{M}_{\mathrm{x}}{ }^{3+}(\mathrm{OH})_{2}\right]^{\mathrm{x+}}\left(\mathrm{X}^{\mathrm{n}-}\right)_{\mathrm{x} / \mathrm{n}} \cdot \mathrm{mH}_{2} \mathrm{O}$ 
without anchoring of $\mathrm{X}^{-}$anions onto the layers, only a few works on the intercalation of molecules bearing phosphonic acids have been reported. ${ }^{[32,33]}$

Phosphonic acids, due to their coordination properties, are widely employed to prepare crystalline hybrid materials ${ }^{[34]}$ that are studied for their porosity, ${ }^{[35,36]}$ ionic conduction, ${ }^{[37,38]}$ magnetic ${ }^{[39,40]}$ or fluorescent ${ }^{[41,42]}$ properties or for their bactericidal effects. ${ }^{[43]}$

Over the recent years, efforts were made on the use of rigid phosphonic acids for the solvothermal one-pot synthesis of hybrid compounds, ${ }^{[44]}$ with the aim to assess the consequences of this rigidity on the topology of the obtained systems. ${ }^{[45]}$ The rigidity results from a direct connection of the phosphonic acid on an aromatic ${ }^{[46]}$ or hetero-aromatic ring ${ }^{[47]}$ acting as a rigid molecular platform. When low symmetrical phosphonic acid compounds like 3-phosphonobenzoic acid (which features an aromatic ring with pro-chiral faces) are reacted with copper salts in solvothermal conditions non-centrosymmetric crystals are obtained. ${ }^{[48]}$ Interestingly, non-centrosymmetric crystals can also be produced with diphosphonic acid as organic precursors. ${ }^{[47]}$ These earliest results motivated the further exploration of diphosphonic acids as precursors of hybrid materials. The choice of the rigid platform is another important parameter. In this respect, fluorene stands as an interesting rigid platform in which the presence of the 5-membered ring breaks the symmetry of the compound. ${ }^{[49,50]}$

In the present paper, we extend the use of fluorene-based compounds proposing novel mono and diphosphonic acids, with various alkyl chains in position 9 of the fluorene unit $\left(-\mathrm{H},-\mathrm{CH}_{3}\right.$ or $\left.-\left(\mathrm{CH}_{2}\right)_{7} \mathrm{CH}_{3}\right)$ (Scheme 1), to foster, so far unexplored, magneto-electric phenomena into $\mathrm{Cu}$ and Co Layered Simple Hydroxides. We address this challenge disussing in the following the synthesis, characterization, structural modeling and magnetic and dielectric properties of new layered hybrid compounds which will be referred to as $\mathbf{A \subset M}$, where A is the mono- or di-phosphonic acid fluorene and $\mathrm{M}$ denotes $\mathrm{Co}$ or $\mathrm{Cu}$ hydroxide layers. 


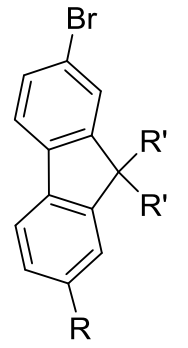

$$
\begin{aligned}
& \text { 1a } \mathrm{R}=\mathrm{H}, \mathrm{R}^{\prime}=\mathrm{H} \\
& \text { 1b } \mathrm{R}=\mathrm{H}, \mathrm{R}^{\prime}=\mathrm{CH}_{3} \\
& \text { 4a } \mathrm{R}=\mathrm{Br}, \mathrm{R}^{\prime}=\mathrm{H} \\
& \text { 4b } \mathrm{R}=\mathrm{Br}, \mathrm{R}^{\prime}=\mathrm{CH}_{3} \\
& \text { 4c } \mathrm{R}=\mathrm{Br}, \mathrm{R}^{\prime}=\left(\mathrm{CH}_{2}\right)_{7}-\mathrm{CH}_{3}
\end{aligned}
$$

$$
\begin{aligned}
& \underset{\mathrm{NiBr}_{2}}{\stackrel{\mathrm{P}(\mathrm{OEt})_{3}}{\longrightarrow}} \\
& \text { Mesitylene } \\
& 160^{\circ} \mathrm{C}
\end{aligned}
$$<smiles>[R]c1ccc2c(c1)C([R])([R])c1cc(P(=O)(OCC)OCC)ccc1-2</smiles>

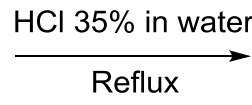<smiles>[R]c1ccc2c(c1)C([R])([R])c1cc(P(=O)(O)O)ccc1-2</smiles>

2a $\mathrm{R}=\mathrm{H}, \mathrm{R}^{\prime}=\mathrm{H}$

3a $\mathrm{R}=\mathrm{H}, \mathrm{R}^{\prime}=\mathrm{H}$

2b $\mathrm{R}=\mathrm{H}, \mathrm{R}^{\prime}=\mathrm{CH}_{3}$

3b $\mathrm{R}=\mathrm{H} \mathrm{R}^{\prime}=\mathrm{CH}_{3}$

5a $\mathrm{R}=\mathrm{PO}(\mathrm{OEt})_{2}, \mathrm{R}^{\prime}=\mathrm{H}$

6a $\mathrm{R}=\mathrm{PO}(\mathrm{OH})_{2}, \mathrm{R}^{\prime}=\mathrm{H}$

5b $\mathrm{R}=\mathrm{PO}(\mathrm{OEt})_{2}, \mathrm{R}^{\prime}=\mathrm{CH}_{3}$

6b $\mathrm{R}=\mathrm{PO}(\mathrm{OH})_{2}, \mathrm{R}^{\prime}=\mathrm{CH}_{3}$

5c $\mathrm{R}=\mathrm{PO}(\mathrm{OEt})_{2}, \mathrm{R}^{\prime}=\left(\mathrm{CH}_{2}\right)_{7}-\mathrm{CH}_{3}$

Scheme 1. Synthesis of the fluorenyl mono and diphosphonic acids used in this work.

\section{Results and discussion}

\subsection{Synthesis of the organic molecules}

The synthesis of the fluorenyl-(di)phosphonic acids 3a-b (monophosphonic acids) and 6a-c (diphosphonic acids) (Scheme 1) was performed in a two-step sequence that starts from the commercially available 2-bromofluorene 1a (2,7-dibromofluorene 4a) and its 9,9-dimethyl analogue 1b (4b) or the 9,9-dioctyl-2,7-dibromofluorene 4c. A nickel assisted Arbuzov reaction (Tavs's reaction) was selected to achieve the $\mathrm{P}-\mathrm{C}$ bond as it is adapted to prepare aryl-mono or polyphosphonates. ${ }^{[51]}$ This reaction requires a careful addition of triethylphosphite on a solution composed of the selected (di)bromofluorenyl derivative 1a-b (4a-c), nickel bromide and mesitylene, heated at $160^{\circ} \mathrm{C}$. After a purification step, the (di)phosphonates 2a-b (5a-c) were isolated in 63 to $83 \%$ yields in a multigram scale. Then, the hydrolysis of the diethyl phosphonate functions into phosphonic acid was efficiently achieved by using concentrated $\mathrm{HCl}$ water solution (35\% in water). The final products $\mathbf{1 a - b}$ (6a-c) were isolated as white solids with good yields (>92\%) and were fully characterized (see Experimental Section and Supporting Information). 


\subsection{Synthesis and characterization of the hybrid compounds}

\subsubsection{Synthesis}

The synthesis of the hybrid compounds was carried out following a generally used procedure consisting in dissolving an excess of the organic molecule in water at relatively high $\mathrm{pH}$ (c.a. 8); then an equivalent volume of ethanol is added along with the starting materials $\mathrm{Cu}_{2}(\mathrm{OH})_{3}(\mathrm{DS})$ and $\mathrm{Co}_{2}(\mathrm{OH})_{3.5}\left(\mathrm{DS}_{0}\right)_{0.5}$ respectively $\left(\mathrm{DS}^{-}\right.$is dodecylsulfate and $\mathrm{DS}_{0}^{-}$is dodecylsulfonate). ${ }^{[26-30]}$ Such kind of preintercalation strategy is often used for the functionalization of layered materials, hexathiohypodiphosphates $\left(\mathrm{MPS}_{3}\right),{ }^{[52,53]}$ zirconium phosphate,${ }^{[54-56]}$ Layered Double Hydroxides (LDH), ${ }^{[57]}$ or layered oxides. ${ }^{[58-60]}$ It consists in prefunctionalizing the starting compound by a molecule which is further removed to allow the insertion of the desired species. In the case of Layered Simple Hydroxides (LSH), we have developed the prefunctionalization by dodecylsulfate or dodecylsulfonate, which is very efficient to allow the insertion-grafting of bulky or fragile molecules. ${ }^{[27,28,30]}$

In the present case, the attempts to insert-graft directly the fluorenyl-mono or diphosphonic acids into $\mathrm{Cu}_{2}(\mathrm{OH})_{3}(\mathrm{OAc})$ or $\mathrm{Co}_{2}(\mathrm{OH})_{3.2}(\mathrm{OAc})_{0.8}$ were unsuccessful, leading to unreacted compounds, multiphasic, badly crystallized compounds, or oxides. The temperatures and durations of the reactions performed with preintercalated compounds $\mathrm{Cu}_{2}(\mathrm{OH})_{3}(\mathrm{DS})$ or $\mathrm{Co}_{2}(\mathrm{OH})_{3.5}\left(\mathrm{DS}_{0}\right)_{0.5}$ were adapted to obtain single-phase materials, while optimizing the crystallinity and avoiding the formation of oxides (Table 1). The successful and complete insertion necessitates the use of an excess of desired molecules, as already observed in the case of carboxylate and sulfonate anchoring functions. ${ }^{[26,27]}$ In the present case, with phosphonic acid anchoring groups, we used a ratio $\mathrm{R}=\mathrm{n}_{\mathrm{PO} 3} / \mathrm{n}_{\text {starting hydroxide }}=2$ for monophosphonic acids and copper-based hydroxide (1.4 for cobalt-based hydroxides) and 4 (2.8) for diphosphonic acids. It is worth noticing that for the non-substituted fluorenes $\mathbf{3 a}$ and 6a it is necessary to use twice the amount of molecule, and to use a slightly higher $\mathrm{pH}$. For their insertion into copper hydroxide, it was necessary to limit drastically the reaction time (15 
min) to avoid formation of oxides. In addition, it has not been possible to insert 3a and $\mathbf{6 a}$ into layered cobalt hydroxide, probably because of the acidity of the proton in position 9 of the fluorene motif.

Table 1. Reaction conditions for the synthesis of the hybrid compounds

\begin{tabular}{|c|c|c|c|c|c|}
\hline & Starting hydroxide & $\mathrm{R}^{\mathrm{a})}$ & $\mathrm{pH}^{\mathrm{b})}$ & $\mathrm{T}$ & $\mathrm{T}[\mathrm{h}]$ \\
\hline $3 a \subset C u$ & $\mathrm{Cu}_{2}(\mathrm{OH})_{3}(\mathrm{DS})$ & 4 & 8.8 & Reflux $\left(82^{\circ} \mathrm{C}\right)$ & 0.25 \\
\hline $3 b \subset \mathrm{Cu}$ & $\mathrm{Cu}_{2}(\mathrm{OH})_{3}(\mathrm{DS})$ & 2 & 8.3 & RT & 70 \\
\hline $3 b \subset C o$ & $\mathrm{Co}_{2}(\mathrm{OH})_{3.5}\left(\mathrm{DS}_{0}\right)_{0.5}$ & 1.4 & 8.3 & RT & 24 \\
\hline $6 a \subset C u$ & $\mathrm{Cu}_{2}(\mathrm{OH})_{3}(\mathrm{DS})$ & 8 & 8.8 & Reflux $\left(82^{\circ} \mathrm{C}\right)$ & 0.25 \\
\hline $6 b \subset \mathrm{Cu}$ & $\mathrm{Cu}_{2}(\mathrm{OH})_{3}(\mathrm{DS})$ & 4 & 8.3 & Reflux $\left(82^{\circ} \mathrm{C}\right)$ & 1 \\
\hline $6 b \subset C o$ & $\mathrm{Co}_{2}(\mathrm{OH})_{3.5}\left(\mathrm{DS}_{0}\right)_{0.5}$ & 2.8 & 8.3 & Reflux $\left(82^{\circ} \mathrm{C}\right)$ & 2 \\
\hline $6 c \subset C u$ & $\mathrm{Cu}_{2}(\mathrm{OH})_{3}(\mathrm{DS})$ & 4 & 8.3 & $70^{\circ} \mathrm{C}$ & 2 \\
\hline $6 c \subset C o$ & $\mathrm{Co}_{2}(\mathrm{OH})_{3.5}\left(\mathrm{DS}_{0}\right)_{0.5}$ & 2.8 & 8.3 & Reflux $\left(82^{\circ} \mathrm{C}\right)$ & 1.5 \\
\hline
\end{tabular}

${ }^{\mathrm{a})} \mathrm{R}=\mathrm{n}_{\mathrm{PO} 3} / \mathrm{n}_{\text {starting hydroxide }} ;{ }^{\mathrm{b})} \mathrm{pH}$ is the $\mathrm{pH}$ of the starting fluorene phosphonic acid aqueous solution before the addition of ethanol

\subsubsection{Characterization}
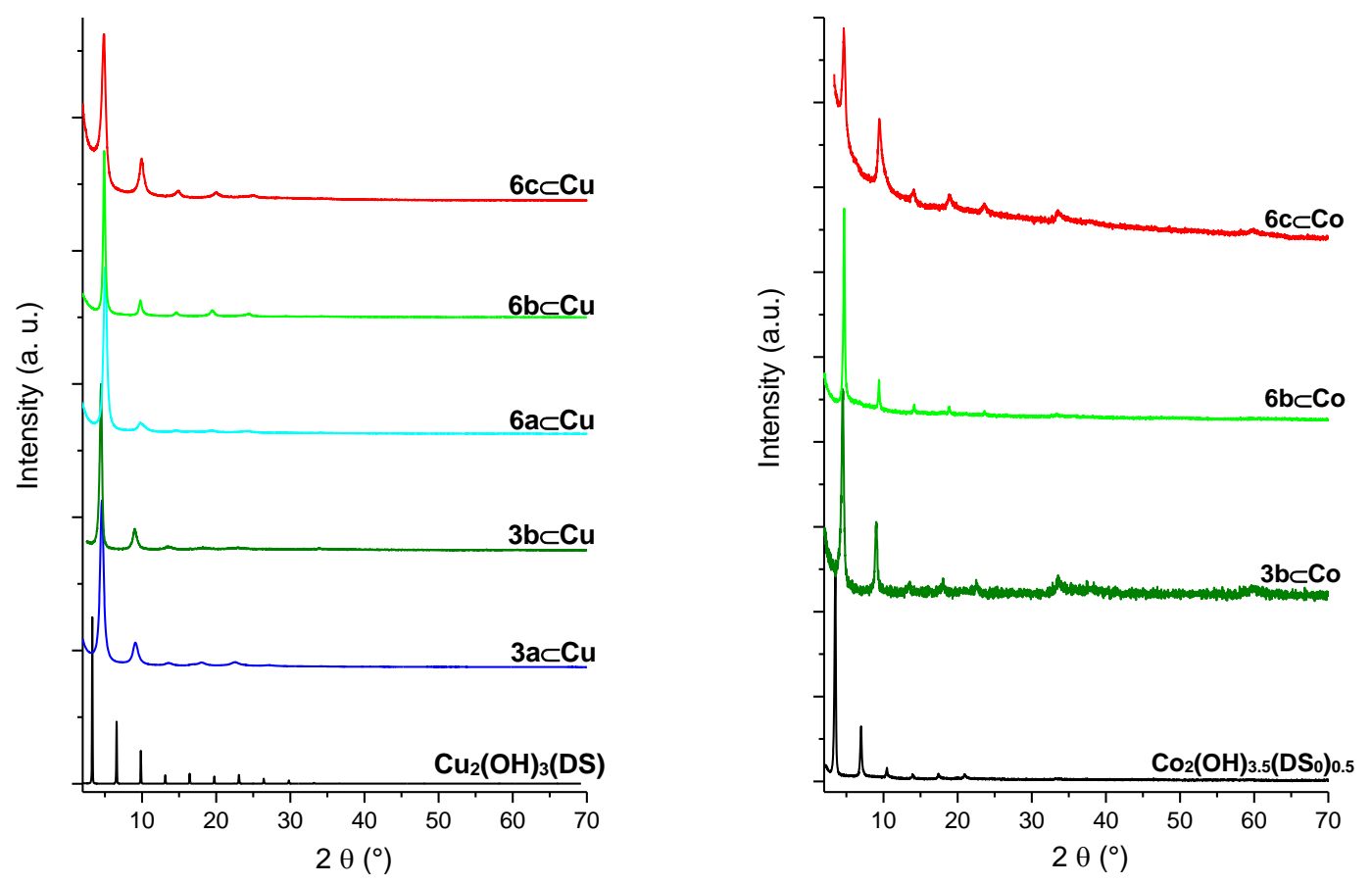

Figure 1. Powder XRD patterns of the Cu-based hybrids (left), and the Co-based hybrids (right). 
The powder X-ray diffraction patterns of the hybrid compounds are presented Figure 1 along with the ones of the starting hydroxides. At low angles, the diagrams show the intense $00 l$ diffraction peaks, up to at least the fourth harmonic, which clearly underlines the lamellar character of the hybrid compounds and provides the basal spacing (Table 2). No diffraction peak coming from the starting compounds is evidenced, and no sulfur atom is detected in elemental analysis (see Experimental Section), which indicates the completeness of the exchange reaction. The cobalt compounds exhibit similar features in the high $2 \theta$ region (inplane diffraction lines) with characteristic asymmetrical peaks at $2 \theta=33.46^{\circ}$ and $2 \theta=59.90^{\circ}$ which suggests a similar turbostratic disorder. ${ }^{[27,61]}$

The abrupt change of the interlamellar spacing for the hybrid compounds with respect to the starting hydroxides $\mathrm{Cu}_{2}(\mathrm{OH})_{3}(\mathrm{DS})$ or $\mathrm{Co}_{2}(\mathrm{OH})_{3.5}\left(\mathrm{DS}_{0}\right)_{0.5}$ is in agreement with the insertion of the fluorene phosphonic acid molecules. Considering the length of the fluorene monophosphonic acids (about $1 \mathrm{~nm}$ ) and the thickness of the inorganic sheets (about $0.2 \mathrm{~nm}$ for the sheets of copper hydroxide, ${ }^{[62]}$ and $0.7 \mathrm{~nm}$ for the triple-deck sheets of cobalt hydroxide ${ }^{[63-65]}$, the interlamellar spacing of the cobalt or copper-based hybrid compounds obtained with fluorene monophosphonic acids is coherent with a double layer arrangement of the molecules, with some possible interpenetration depending on the inclination angle. For the fluorene diphosphonic acids (length of about $1.2 \mathrm{~nm}$ ), the observed interlamellar spacing obtained for cobalt based compounds is coherent with a pillaring arrangement of the diphosphonic acids, almost perpendicular to the inorganic layers. Yet, for copper based compounds the hypothesis of a bi-grafting of the molecules onto the inorganic layers would lead to an interlamellar spacing of about $1.4 \mathrm{~nm}$, much smaller than the observed one.

In order to solve this apparent discrepancy and to shed light on the molecular arrangement of fluorene mono- and di-phosphonic acids in the interlayer environment for such systems we made use of first-principles molecular dynamics simulations (FPMD) within the density 
functional theory (DFT) framework to investigate the structure, the chemical bonding and the related dynamic properties of hybrid systems. This computational tool allowed us to unveil the interlayer chemical arrangements for $3 \mathbf{a} \subset \mathbf{C u}$ and $\mathbf{6} \mathbf{a} \subset \mathbf{C u}$, providing support to the picture of a tilted orientation of $\mathbf{3 a}$ in copper hydroxide, a detail elusive to experimental probes. Such a tilted configuration for $\mathbf{3 a}$ induces a slightly interdigitation of the fluorene moieties linked to opposite copper hydroxide layers and results consistent with the measured interlayer distance (1.9 nm). Instead, for $\mathbf{6 a} \subset \mathbf{C u}$ a more complex arrangement is found, with the fluorene diphosphonic acid chemically anchored to the copper hydroxide layer through one phosphonate group $\left(\mathrm{Cu}-\mathrm{O}_{6 \mathrm{a}}\right.$ distance in the range of $\left.0.26-0.32 \mathrm{~nm}\right)$ and the remaining one at a greater interatomic distance $\left(\mathrm{Cu}-\mathrm{O}_{6 \mathbf{a}}\right.$ distance of about $\left.0.55 \mathrm{~nm}\right)$ with respect to the opposite inorganic layer. This configuration allows for the coordination of a water molecule by the copper atoms, replacing the stabilizing role of the phosphonic acid groups. In paragraph 2.2, the chemical bonding properties and structural organization involved in the interlayer environments of $\mathbf{3 a} \subset \mathbf{C u}$ and $\mathbf{6 a} \subset \mathbf{C u}$ are detailed and discussed, as well as the fundamental role of water molecules and the H-bonding network they promote.

Unfortunately, the precise structure of the inorganic layers for layered cobalt hydroxide is still unknown due to static disorder of the $\alpha-\mathrm{Co}(\mathrm{OH})_{2}$ inorganic layers. ${ }^{[66,67]}$ This prevents performing the same kind of approach for the analysis of the interaction between the phosphonic acid groups and the cobalt hydroxide layers. Yet, it is worth underlining that in the case of cobalt-based hybrids functionalized by fluorene di-phosphonic acids, the experimental interlamellar distance is compatible with a pillaring arrangement of the molecules, the phosphonic acid moieties being coordinated to tetrahedral cobalt sites.

Table 2. Formula and interlamellar spacing of the hybrid compounds

\begin{tabular}{ccc}
\hline & Formula & $\begin{array}{c}d \\
{[\mathrm{~nm}]}\end{array}$ \\
\hline $\mathbf{3 a} \subset \mathrm{Cu}$ & $\mathrm{Cu}_{2}(\mathrm{OH})_{3.56}\left(\mathrm{C}_{13} \mathrm{H}_{11} \mathrm{O}_{3} \mathrm{P}\right)_{0.44} \cdot 2.7 \mathrm{H}_{2} \mathrm{O}$ & 1.96 \\
\hline
\end{tabular}




\begin{tabular}{lll}
\hline $3 \mathbf{b} \subset \mathbf{C u}$ & $\mathrm{Cu}_{2}(\mathrm{OH})_{3.5}\left(\mathrm{C}_{15} \mathrm{H}_{13} \mathrm{O}_{3} \mathrm{P}\right)_{0.50} \cdot 2.3 \mathrm{H}_{2} \mathrm{O}$ & 1.93 \\
$3 \mathbf{b} \subset \mathbf{C o}$ & $\mathrm{Co}_{2}(\mathrm{OH})_{3.66}\left(\mathrm{C}_{15} \mathrm{H}_{13} \mathrm{O}_{3} \mathrm{P}\right)_{0.34} \cdot 1.3 \mathrm{H}_{2} \mathrm{O}$ & 1.96 \\
$6 \mathbf{a} \subset \mathrm{Cu}$ & $\mathrm{Cu}_{2}(\mathrm{OH})_{3.54}\left(\mathrm{C}_{13} \mathrm{H}_{10} \mathrm{O}_{6} \mathrm{P}_{2}\right)_{0.23} \cdot 3.5 \mathrm{H}_{2} \mathrm{O}$ & 1.80 \\
$6 \mathbf{b} \subset \mathbf{C u}$ & $\mathrm{Cu}_{2}(\mathrm{OH})_{3.6}\left(\mathrm{C}_{15} \mathrm{H}_{12} \mathrm{O}_{6} \mathrm{P}_{2}\right)_{0.20} \cdot 2.7 \mathrm{H}_{2} \mathrm{O}$ & 1.82 \\
$6 \mathbf{b} \subset \mathbf{C o}$ & $\mathrm{Co}_{2}(\mathrm{OH})_{3.42}\left(\mathrm{C}_{15} \mathrm{H}_{13} \mathrm{O}_{6} \mathrm{P}_{2}\right)_{0.29} \cdot 1.7 \mathrm{H}_{2} \mathrm{O}$ & 1.88 \\
$6 \mathbf{c} \subset \mathbf{C u}$ & $\mathrm{Cu}_{2}(\mathrm{OH})_{3.68}\left(\mathrm{C}_{29} \mathrm{H}_{42} \mathrm{O}_{6} \mathrm{P}_{2}\right)_{0.16} \cdot 2.5 \mathrm{H}_{2} \mathrm{O}$ & 1.78 \\
$6 \mathbf{c} \subset \mathbf{C o}$ & $\mathrm{Co}_{2}(\mathrm{OH})_{3.8}\left(\mathrm{C}_{29} \mathrm{H}_{42} \mathrm{O}_{6} \mathrm{P}_{2}\right)_{0.10} \cdot 2.9 \mathrm{H}_{2} \mathrm{O}$ & 1.88 \\
\hline
\end{tabular}

The SEM images of compounds $\mathbf{3 b \subset C u}$ and $\mathbf{6 c c} \subset \mathbf{C o}$ are shown in Figure $\mathbf{S 2 5}$ and are representative of all the hybrid compounds described here. The materials are obtained as thin platelets, in agreement with their lamellar structure.

The insertion rates, determined from elemental analysis (Table 2), are comprised between 0.34 and 0.5 molecule per formula unit in the case of monophosphonic acids and between 0.10 and 0.29 molecule per formula unit in the case of diphosphonic acids. In terms of phosphonic groups per formula unit, the insertion rates are thus very similar between monophosphonic acids and diphosphonic acids. It is nevertheless worth remarking that the insertion rate is significantly smaller for the bulky fluorene $\mathbf{6 c}$, bearing long lateral alkyl chains, than for fluorenes bearing only $-\mathrm{H}$ or $-\mathrm{CH}_{3}$ groups in position 9. This observation, and the fact that the insertion rates deviate significantly from 1.0 phosphonic group per formula unit for copper-based hybrids and from 0.5 phosphonic group per formula unit for cobalt-based hybrids indicate that the exchange process is likely not topotactic, but rather processes via dissolution-recrystallisation. ${ }^{[68,69]}$

Infrared spectra of all hybrid compounds exhibit a band at $1600 \mathrm{~cm}^{-1}$ ascribed to the $\mathrm{P}(\mathrm{O})(\mathrm{OH})$ group $^{[70]}$ as well as a band around $1220 \mathrm{~cm}^{-1}$ corresponding to the $\mathrm{P}=\mathrm{O}$ band (Figure S26). ${ }^{[33,71,72]}$ It is however extremely difficult to assign precisely the other bands in the neighbouring region $\left(900-1250 \mathrm{~cm}^{-1}\right)$ with respect to the phosphonic acid group vibrational modes, and even more difficult to attempt to ascertain the grafting mode of the phosphonates. Such an attribution can be performed relatively easily in the case of 
carboxylate anchoring functions, ${ }^{[73,74]}$ and with more difficulties in the case of sulfonate anchoring functions. ${ }^{[75-78]}$ In the case of phosphonic acids, the attribution of the IR bands is the subject of various contradictory assertions in the litterature. ${ }^{[70-72,79-82]}$ In the present case, it is all the more complicated due to the large number of bands present in this region of the spectra. It is however possible to spot the fingerprint of each molecule in the corresponding hybrid compound with bands such as the ones present at 1604, 1469, 1446 and $1402 \mathrm{~cm}^{-1}$ that likely correspond to the $\mathrm{C}-\mathrm{C}$ rings stretching modes in the fluorene moieties. ${ }^{[83,84]}$ Other bands present in the $1280-1000 \mathrm{~cm}^{-1}$ region and corresponding to the $\mathrm{C}-\mathrm{H}$ inplane bending of the fluorenes ${ }^{9}$ cannot be told apart from each other due to the presence of multiple other peaks.

Finally, the UV-Visible reflectance spectra of $\mathbf{6 c} \subset \mathbf{C u}$ and $\mathbf{6 c} \subset \mathbf{C o}$ are presented in Figure S27 (after Kubelka Munk correction), along with the spectra of the starting fluorene. They are representative of the spectra of all hybrid compounds described here. The spectra of the copper hydroxide-based compounds are dominated by the $\mathrm{O} \rightarrow \mathrm{Cu}$ charge transfer band (which overlaps with the intense intense absorption of the fluorene moiety) and the weaker d-d band at $710 \mathrm{~nm}$, responsible for the blue color of the compounds. For the cobalt-hydroxide based compounds, the UV part of the spectra is also dominated by the $\mathrm{O} \rightarrow \mathrm{Co}$ charge transfer band and the $\pi \rightarrow \pi^{*}$ bands of the fluorene moiety. At lower energies, two series of bands can be observed. The bands observed at $1550 \mathrm{~nm}, 635 \mathrm{~nm}$ and $592 \mathrm{~nm}$ can be attributed respectively to ${ }^{4} \mathrm{~A}_{2}(\mathrm{~F}) \rightarrow{ }^{4} \mathrm{~T}_{2}(\mathrm{~F}),{ }^{4} \mathrm{~A}_{2}(\mathrm{~F}) \rightarrow{ }^{4} \mathrm{~T}_{1}(\mathrm{~F})$ and ${ }^{4} \mathrm{~A}_{2}(\mathrm{~F}) \rightarrow{ }^{4} \mathrm{~T}_{1}(\mathrm{P})$ transitions of $\mathrm{HS} \mathrm{d}^{7} \mathrm{Co}(\mathrm{II})$ in tetrahedral sites, whereas the bands observed at $1250 \mathrm{~nm}$ and $494 \mathrm{~nm}$ can be attributed respectively to ${ }^{4} \mathrm{~T}_{1 \mathrm{~g}}(\mathrm{~F}) \rightarrow{ }^{4} \mathrm{~T}_{2 \mathrm{~g}}(\mathrm{~F})$ and ${ }^{4} \mathrm{~T}_{1 \mathrm{~g}}(\mathrm{~F}) \rightarrow{ }^{4} \mathrm{~T}_{1 \mathrm{~g}}(\mathrm{P})$ transitions of $\mathrm{HS} \mathrm{d}{ }^{7} \mathrm{Co}(\mathrm{II})$ in octahedral sites, ${ }^{[85]}$ in accordance with the proposed structure ${ }^{[27,66,67,86]}$ and with the magnetic behavior (see below).

Despite all fluorene derivatives used here $(\mathbf{3 a}, \mathbf{3 b}, \mathbf{3 c}, \mathbf{6} \mathbf{a}, \mathbf{6 b}$ and $\mathbf{6 c})$ are luminescent (emission around $385 \mathrm{~nm}$ when excited at $340 \mathrm{~nm}$ ), only hybrids containing the fluorene 
bearing the longest lateral chains $(\mathbf{6 c} \subset \mathbf{C u}$ and $\mathbf{6 c} \subset \mathbf{C o})$ are still luminescent, the fluorene luminescence in the other hybrid compounds being totally quenched. This suggests that the quenching is essentially due to intermolecular interactions between fluorene moieties in the interlamellar spacing, as already observed for oligothiophenes ${ }^{[86]}$ and oligophenylenevinylenes. ${ }^{[87]}$ For the hybrids containing the bulky fluorene $\mathbf{6 c}$, the density and arrangement of the inserted molecules is probably more favorable to avoid quenching of the luminescence. Yet the luminescence intensity is quite small, an important part of the incident light being absorbed by the inorganic host. Finally, for $\mathbf{6 c} \subset \mathbf{C u}$ the luminescence occurs at the same wavelength as $\mathbf{6 c}$ alone $(385 \mathrm{~nm})$, whereas $\mathbf{6 c} \subset \mathbf{C o}$ fluoresces at a slightly larger wavelength (405 nm) which suggests different host-guest interactions (Figure S28).

\subsection{Interlayer chemical bonding and the role of water}

Computer simulations resorting to advanced theoretical methods provide useful information and complement experiments on layered materials, such as LSH, by unveiling the interplay between molecular architecture and electronic properties for this class of hybrid materials. In particular, density functional theory (DFT) based first-principles molecular dynamics (FPMD) provides a reliable description of atomic forces, thereby making possible the assessment of the bonding interactions of multicomponent systems. FPMD has come to a full maturity in terms of technical developments and efficiency, being ready to be exploited on composite systems where an accurate description of the chemical bonding is a necessary requirement to shed light on their structure-property correlations. ${ }^{[26]}$ Herein, we take full advantage of a thoughtful, well-established simulation methodology benchmarked over a wealth of results for copper hydroxide acetate, a prototypical system for the present class of LSH materials. ${ }^{[88-90]}$ 
Recently, such methodology has been fostered to disentangle the role of $2 \mathrm{D} / 3 \mathrm{D}$ spinpolarization interactions in copper hydroxide acetate. ${ }^{[91]}$

This type of dynamical simulations have been used here identify the local molecular organization of the interlayer environment of $\mathbf{3 a} \subset \mathbf{C u}$ and $\mathbf{6} \mathbf{a} \subset \mathbf{C u}$ systems. Figure 2a shows a typical stable configuration of the $\mathbf{3 a} \subset \mathbf{C u}$. For such system, the fluorene mono-phosphonic acid is found to be chemically anchored to the copper hydroxide layer through the interaction of three $\mathrm{Cu}$ atoms and one $\mathrm{O}$ atom of the phosphonate group within an equilibrium distance in the range of $0.26-0.32 \mathrm{~nm}$. Several local chemical scenarios have been explored for the phosphonate group, finding the mono-protonated form (Fluorene- $\mathrm{PO}_{3} \mathrm{H}^{(-)}$) the most stable one. The optimized system, equilibrated at finite temperature for about $5 \mathrm{ps,} \mathrm{shows} \mathrm{the} \mathrm{fluorene}$ moieties homogeneously tilted with respect to the plane of copper hydroxide by an angle of $\sim 66^{\circ}$, which induces a partial interpenetration of the aromatic parts (Figure $2 \mathbf{b}$ ).

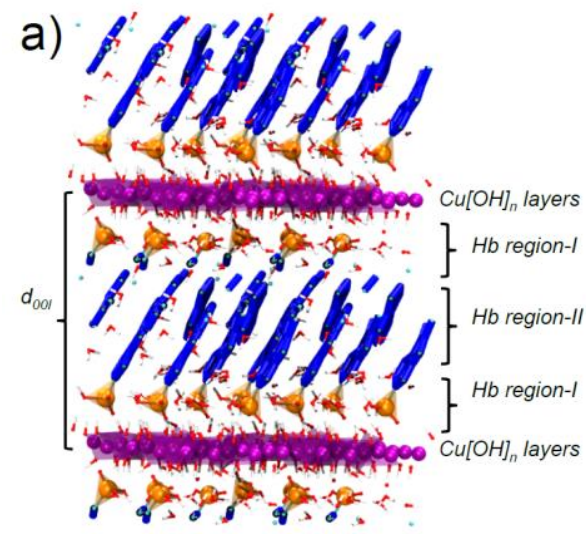

b)

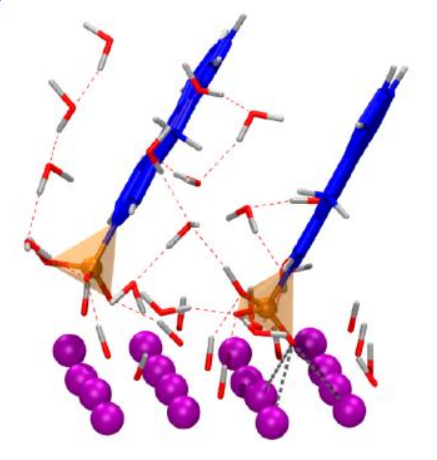

c)

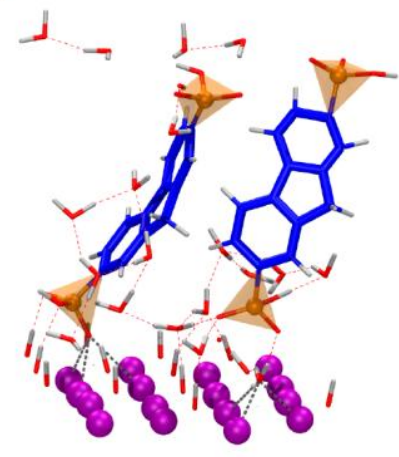

Figure 2. a) Typical configuration of $\mathbf{3 a} \subset \mathbf{C u}$ obtained via FPMD simulations (visualized supercell replicated $2 \times 2 \times 2$ along $x, y$, and $z$ for clearness). The interlamellar distance $\left(d_{001}\right)$, copper hydroxide layers $\left(\mathrm{Cu}[\mathrm{OH}]_{n}\right)$ as well as the regions corresponding to H-bonding type-I and type-II are also indicated. Color legend: $\mathrm{Cu}$ atoms, purple; $\mathrm{P}$ atoms and polyhedra, orange; $\mathrm{C}$ skeleton of fluorene groups, blue; $\mathrm{O}$ atoms, red; and $\mathrm{H}$ atoms, grey. The local bonding environments surrounding the phosphonate groups $\left(-\mathrm{PO}_{3} \mathrm{H}\right)$ for $\mathbf{3 a} \subset \mathbf{C u}$ and $\mathbf{6} \mathbf{a} \subset \mathbf{C u}$ are visualized in (b) and (c), respectively. The interaction between $\mathrm{Cu}$ atoms with the $\mathrm{O}$ atoms of the $-\mathrm{PO}_{3} \mathrm{H}$ groups and the $\mathrm{O}$ atoms of the water molecules are indicated as gray dashed lines. The H-bonding network is highlighted in red dashed lines. 
For $\mathbf{6 a} \subset \mathbf{C u}$, we found the fluorene di-phosphonic acids to be stably anchored to the copper hydroxide layer through one phosphonate group, chemically interacting with $\mathrm{Cu}$ atoms as similarly as for the $\mathbf{3 a} \subset \mathbf{C u}$. However, the second phosphonic group (opposite attached to the fluorene moiety) remains at a larger distance with respect to the opposite $\mathrm{Cu}$ layer at an interatomic distance of $0.55 \mathrm{~nm}$ (Figure 2c). Such configuration allows a water molecule to fit the space in-between the phosphonate group and the copper layer and to be coordinated by the three $\mathrm{Cu}$ atoms with distances of $0.23-0.27 \mathrm{~nm}$. Contrary to $\mathbf{3 a} \subset \mathbf{C u}$, in the case of $\mathbf{6 a} \subset \mathbf{C u}$ the fluorene moieties are not homogeneously tilted with respect to the $\mathrm{Cu}$ layer and the tilting angle can range from $60^{\circ}$ to $75^{\circ}$. This configurational difference can be explained by the larger free interlayer volume of $\mathbf{6 a} \subset \mathbf{C u}$, having $1 / 2$ of the fluorene moieties within the interlayer with respect to $\mathbf{3 a} \subset \mathbf{C u}$. This factor allows $\mathbf{6 a}$ to have a greater mobility within the interlayer environment.

We also investigated the role of water molecules within the interlayer and for both systems we found common observations. To investigate the role of water we have analyzed the $\mathrm{H}$ bonding network in terms of its electronic structure. To this aim, maximally localized Wannier functions (WFCs) have been proven to provide a powerful tool to rationalize the electronic structure of water ${ }^{[92,93]}$ as well complex disordered systems. ${ }^{[94,95]}$ The center of the charge density associated with a Wannier orbital can be thought of as representing an electron pair. Each oxygen atom is surrounded by four such centers (see Figure 3a). Two are at a longer distance (0.48-0.52 $\AA$ ) from the oxygen, along the $\mathrm{O}-\mathrm{H}$ bond axis, and can be interpreted as the $\sigma$-bonding pairs of the water molecule, whereas the other two are located at a shorter distance $(0.30-0.34 \AA)$ from the $\mathrm{O}$ atom and correspond to the lone pairs.

Within the interlayer regions of $\mathbf{3 a} \subset \mathbf{C u}$ and $\mathbf{6} \mathbf{a} \subset \mathbf{C u}$, water molecules are found to be interacting with both the hydroxide groups of the copper hydroxide layers as well as the phosphonates groups by promoting an extended network of H-bonds. In these systems, a 
hydrogen bond involves three atoms: the hydrogen $\mathrm{H}$, the oxygen atom $\mathrm{O}$ to which it is covalently bound and the acceptor oxygen $\mathrm{O}^{\prime}$, being the one of neighboring water molecules or of the phosphonate groups. The proton transfer coordinate $v=d(\mathrm{O}-\mathrm{H})-d\left(\mathrm{O}^{\prime}-\mathrm{H}\right)$ provides a convenient structural order parameter to characterize the H-bonding network. ${ }^{[96]}$ Values of $\boldsymbol{v}>$ $-1.25 \AA$ indicate the occurence of a "well-formed" H-bonding. ${ }^{[96]}$ Figure 3b and 3c show the joint probability distributions of the proton-transfer coordinate and the one of the distances of the WFCs to the corresponding oxygen ( $\mathrm{O}$ and $\mathrm{O}^{\prime}$, respectively). This analysis of the positions of the WFCs as a function of the proton-transfer coordinate $v$ demonstrates unambiguously that the local fluctuations of the H-bonding are associated with major rearrangements of the electron density. These results show that both $\mathbf{3 a \subset C u}$ and $\mathbf{6 a} \subset \mathbf{C u}$ interlayers are characterized by an extended H-bonding network. Both systems show two main peaks in terms of $\boldsymbol{v}$ (within -1.1 to $0.9 \AA$ ) and within $\boldsymbol{v}\left(-0.8\right.$ to $-0.7 \AA$ ), respectively, for similar $d_{\mathrm{OX}}$ $\left(d_{\mathrm{O}^{\prime} \mathrm{X}^{\prime}}\right)$ distances. These two slightly different $\mathrm{H}$-bonding interactions are ascribed to the $\mathrm{H}-$ bonds promoted by water molecules with the oxygen atoms of the phosphonate groups and with other neighboring water molecules (and hydroxide groups coordinating the $\mathrm{Cu}$ layers), respectively.

These results show that both $\mathbf{3} \mathbf{C} \subset \mathbf{C u}$ and $\mathbf{6 a} \subset \mathbf{C u}$ interlayers are characterized by an extended H-bonding network, that stabilizes the interlayer arrangement of both fluorene mono- and diphosphonic acids. In fact, in the completely dehydrated systems both 3a and $\mathbf{6 a}$ were not found stable along our FPMD simulations. Such behaviours can be ascribed to the low interlayer density of the phosphonic acids leaving a large empty interlayer space. Indeed, a test with a higher density of fluorene mono-phosphonic acid $\left(\mathrm{Cu}_{2}(\mathrm{OH})_{3}\left(\mathrm{C}_{13} \mathrm{H}_{11} \mathrm{O}_{3} \mathrm{P}\right)_{1} \cdot 3 \mathrm{H}_{2} \mathrm{O}\right)$ resulted in a stable configuration. However, such larger density has not been obtained by synthesis.

Considering the stoichiometries experimentally obtained, we can further split the interlayer environment of $\mathbf{3 a} \subset \mathbf{C u}$ and $\mathbf{6 a} \subset \mathbf{C u}$ in two different regions: (i) a first one located within 0.6 
$\mathrm{nm}$ from the $\mathrm{Cu}$ atoms plane and the center of the interlayer and (ii) a second region at distances larger than $0,6 \mathrm{~nm}$ from the $\mathrm{Cu}$ layers. The H-bonds networks within the two different regions are characterized by different properties. Specially, in region-I the $\mathrm{H}-$ bonding network is promoted by the involvement of water molecules, hydroxide groups, and phosphonates groups, whereas in region-II the H-bonding is promoted uniquely by the water molecules. This difference can be made more quantitative by analyzing the electric molecular dipole moment of $\mathrm{H}_{2} \mathrm{O}$ molecules. Figure 3d shows the water molecular dipole computed employing the analysis of the WFCs. The dipole moment of water molecules within the center of the interlayer (within the fluorene moieties environment) is slightly lower than the dipole of water molecules in the proximity of the copper hydroxide layers and phosphonate groups (2.6 D vs $2.9 \mathrm{D})$. This is indicative of the fact that the electric field induced by surrounding molecules enhances the dipole moment of the single water molecule. ${ }^{[92,97]}$

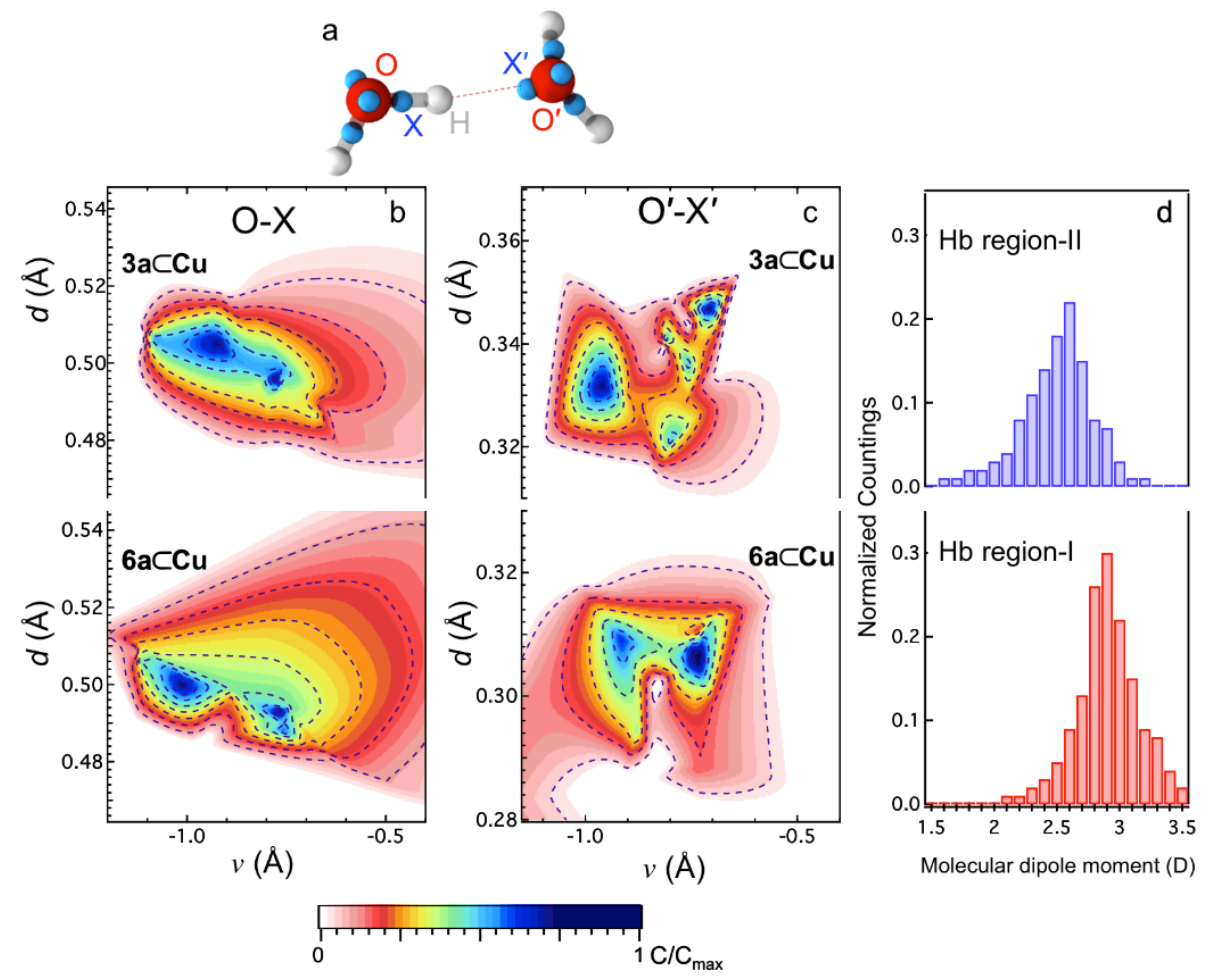

Figure 3. a) Schematic representation of a typical hydrogen bond promoted by two water molecules. The oxygen $(\mathrm{O})$, hydrogen $(\mathrm{H})$ and WFCs $(\mathrm{X})$ are indicated in red, gray, and cyan respectively. The acceptor oxygen and one of its lone pair WFC are indicated as $\mathrm{O}^{\prime}$ and $\mathrm{X}^{\prime}$, respectively. b,c) Joint probability distributions of the proton-transfer coordinate $v=d(\mathrm{O}-\mathrm{H})$ $d\left(\mathrm{O}^{\prime}-\mathrm{H}\right)$ and of the distances of these oxygen atoms ( $\mathrm{O}-\mathrm{X}$ in $\left.\mathrm{b}\right)$ and $\mathrm{O}^{\prime}-\mathrm{X}^{\prime}$ in c)) with their 
corresponding Wannier centers. The upper and lower plots correspond to the data analyzed for $\mathbf{3 a} \subset \mathbf{C u}$ and $\mathbf{6} \mathbf{a} \subset \mathbf{C u}$, respectively. d) Normalized distributions of the modulus of the molecular dipole of water molecules in the central (Hb region-II in the upper part of 4-d) and the interface $(\mathrm{Hb}$ region-I, lower part of 4-d) regions of the interlayer hydrogen bonding network for $\mathbf{3 a} \subset \mathbf{C u}$.

\subsection{Magnetic properties}

The magnetic behaviors of the copper compounds $3 \mathbf{a} \subset \mathbf{C u}, \mathbf{3 b} \subset \mathbf{C u}, \mathbf{6 a} \subset \mathbf{C u}, \mathbf{6 b} \subset \mathbf{C u}$ and 6c $\subset \mathbf{C u}$ are similar (Table 3 and Figure S29 and S30). The inverse of the susceptibility (not shown) varies linearly with the temperature (above $200 \mathrm{~K}$ ) and can be fitted by the CurieWeiss law, giving $C=0.72,0.94,0.76,0.71$ and $0.95 \mathrm{emu} \cdot \mathrm{K} \cdot \mathrm{mol}^{-1}$ for $\mathbf{3 a} \subset \mathbf{C u}, \mathbf{3 b \subset C u}$, $3 \mathbf{c} \subset \mathbf{C u}, \mathbf{6 a} \subset \mathbf{C u}, \mathbf{6 b} \subset \mathbf{C u}$ and $\mathbf{6 c} \subset \mathbf{C u}$ respectively, in the expected range for two $\mathrm{Cu}$ (II) ions. ${ }^{\left[{ }^{[2,98}\right]}$ The $\chi T$ products decrease regularly when decreasing the temperature, indicating an overall antiferromagnetic behavior, without any magnetic ordering down to the lowest accessible temperature $(1.8 \mathrm{~K})$.

Table 3. Summary of the magnetic characteristics of the hybrid compounds

\begin{tabular}{|c|c|c|c|c|c|}
\hline & $\begin{array}{c}C \\
{[\mathrm{emu} \mathrm{K} / \mathrm{mol}]}\end{array}$ & $\begin{array}{c}\theta \\
{[\mathrm{K}]}\end{array}$ & $\begin{array}{l}\mathrm{T}_{\mathrm{C}} \\
{[\mathrm{K}]}\end{array}$ & $\begin{array}{c}\mathrm{M}_{7 \mathrm{~T}} \text { at } 1.8 \mathrm{~K} \\
{\left[\mu_{\mathrm{B}}\right]}\end{array}$ & $\begin{array}{c}\mu_{0} \mathrm{H}_{\mathrm{C}} \text { at } 1.8 \mathrm{~K} \\
{[\mathrm{~T}]}\end{array}$ \\
\hline $3 a \subset C u$ & 0.72 & -12.9 & I & 0.39 & I \\
\hline $3 b \subset C u$ & 0.94 & -31.7 & I & 0.49 & I \\
\hline $6 \mathrm{a} \subset \mathrm{Cu}$ & 0.76 & -30.1 & I & 0.30 & I \\
\hline $6 b \subset C u$ & 0.71 & -3.3 & I & $0.50^{*}$ & I \\
\hline $6 c \subset C u$ & 0.95 & -19.9 & I & 0.57 & I \\
\hline $3 b \subset C o$ & 6.09 & -21.7 & 11.8 & 2.43 & 0.20 \\
\hline $6 b \subset C o$ & 5.95 & -22.4 & 11.9 & 2.43 & 0.33 \\
\hline $6 c \subset C o$ & 6.02 & -13.6 & $17.8 / 11.0 / 6.3$ & 2.92 & 0.22 \\
\hline
\end{tabular}

The magnetic behaviors of the cobalt compounds $3 \mathbf{b} \subset \mathbf{C o}, \mathbf{6 b} \subset \mathbf{C o}$ and $\mathbf{6 c} \subset \mathbf{C o}$ are also similar to each other (Table 3 and Figure S31, 4 and 5). The Curie constants range between 5.95 and $6.09 \mathrm{emu} \cdot \mathrm{K} \cdot \mathrm{mol}^{-1}$, in agreement with a mixture of tetrahedral and octahedral high spin $\mathrm{Co}(\mathrm{II})$ 
ions, with $C_{\text {tetra }}=2.2$ to $2.8 \mathrm{emu} \cdot \mathrm{K} \cdot \mathrm{mol}^{-1}$ for one $\mathrm{Co}(\mathrm{II})$ ion, and $C_{\text {octa }}=2.8$ to $3.4 \mathrm{emu} \cdot \mathrm{K} \cdot \mathrm{mol}^{-}$ ${ }^{1} \cdot{ }^{98,99]}$ Upon cooling, the $\chi \mathrm{T}$ products of the three cobalt hybrids go through a minimum around $80 \mathrm{~K}$. This small decrease is well understood on the basis of spin-orbit coupling and/or antiferromagnetic interactions between the Co(II) moments (Figure S31). ${ }^{[100]}$ Below this minimum, the observed steep increase of the $\chi \mathrm{T}$ products can be related to the occurrence of long-range ferrimagnetic order, supported by the occurrence of an out of phase signal in the imaginary part of the ac susceptibility, $\chi$ " (Figure 4). The ordering temperatures were determined from the maximum of the real part of the ac susceptibility ( $\mathrm{f}=95 \mathrm{~Hz}, \mu_{0} \mathrm{H}_{\mathrm{ac}}=0.3$ mT) (Figure 4 and Table 3).

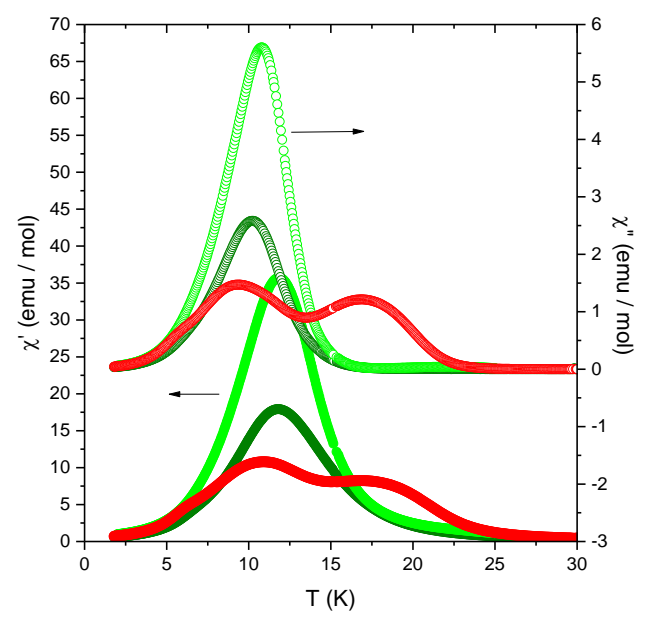

Figure 4. In phase $\left(\chi^{\prime}\right)$ (full circles) and out of phase ( $\chi$ ") (open circles) magnetic susceptibilities measured in an ac field of $0.3 \mathrm{mT}$ at $95 \mathrm{~Hz}$ for $3 \mathbf{b \subset C o}$ (dark green), $\mathbf{6 b \subset C o}$ (green) and $\mathbf{6 c} \subset \mathbf{C o}$ (red).

The fact that the ordering temperatures hardly change when changing the inserted fluorene (the interlamellar distance remaining almost unchanged) is in agreement with an interlayer coupling via dipolar interactions. ${ }^{[30,101]}$ Finally it should be noted that the ac peaks are relatively large, or, for $\mathbf{6 c} \subset \mathbf{C o}$ show two peaks at $17.8 \mathrm{~K}$ and $11.0 \mathrm{~K}$ and a small shoulder around $6.3 \mathrm{~K}$ for $\chi$ ' $(17.0 \mathrm{~K}, 9.3 \mathrm{~K}$ and $5.8 \mathrm{~K}$ for $\chi$ ”). This suggests a distribution of ordering temperatures, not unusual for layered magnets. ${ }^{[86,102,103]}$ 
The ferromagnetic-type ordering of cobalt-based hybrids is further confirmed by the magnetization vs. field curves at low temperature (Figure 5) which shows the presence of hysteresis loops, with coercive fields ranging from $0.20 \mathrm{~T}$ for $\mathbf{3 b \subset C o}$ to $0.33 \mathrm{~T}$ for $\mathbf{6 b \subset C o}$ (Table 3).

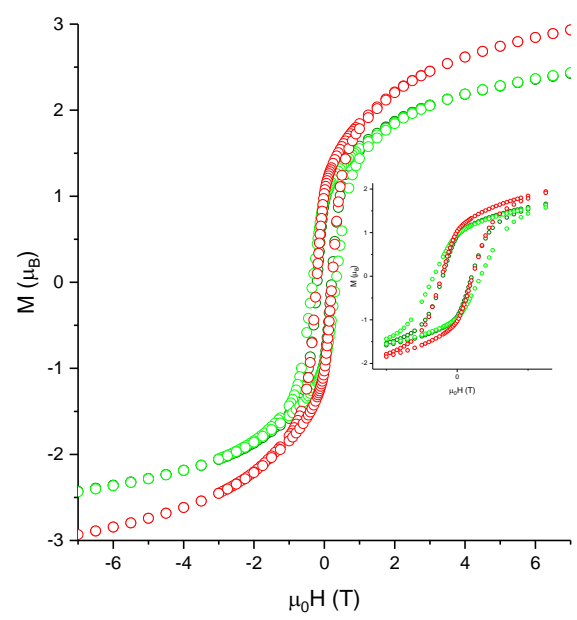

Figure 5. Magnetization vs. field at $1.8 \mathrm{~K}$ for $\mathbf{3 b \subset C o}$ (dark green), $\mathbf{6 b \subset C o}$ (green) and 6cсCo (red).

The low value of the moments at high field $\left(\mathrm{M}(7 \mathrm{~T})=2.4,2.4\right.$ and $2.9 \mu_{\mathrm{B}}$ for $\mathbf{3 b \subset C o ,} \mathbf{6 b \subset C o}$ and $6 \mathbf{c} \subset \mathrm{Co}$ respectively at $1.8 \mathrm{~K}$ ) compared to the expected value for a total alignment of the moments (4-6 $\mu_{\mathrm{B}}$ for two $\mathrm{Co}(\mathrm{II})$ ) confirms a ferrimagnetic ordering, resulting from an unbalanced antiparallel alignment of the moments lead by tetrahedral and octahedral cobalt ions. ${ }^{[100]}$ Indeed, considering for octahedral $S=3 / 2, L=1 \mathrm{Co}(\mathrm{II})$ a magnetization saturation value $\mathrm{M}_{\mathrm{S}}=2.87 \mu_{\mathrm{B}}$ found in $\mathrm{Co}_{2}(\mathrm{OH})_{3}\left(\mathrm{NO}_{3}\right)$ which contains exclusively octahedral sites, ${ }^{[104]}$ and for a tetrahedral $S=3 / 2 \operatorname{Co}(\mathrm{II})$ ion $\mathrm{M}_{\mathrm{S}}=3 \mu_{\mathrm{B}}$, we can calculate a site ratio $\mathrm{Oh}: \mathrm{Td} \approx 76: 24$ for $\mathbf{3 b \subset C o}$ and $\mathbf{6 b \subset C o}$ and 68:32 for $\mathbf{6 c c C} \subset \mathbf{C o}$, in good agreement with what was found from the chemical formulations.

\subsection{Magneto-electric behavior}




\section{6cсCo}

The magnetocapacitance was measured for two different geometries, i.e. $\mathrm{E}_{\mathrm{ac}} / / \mathrm{B}$ and $\mathrm{E}_{\mathrm{ac}} \perp \mathrm{B}$. The most complete data set has been recorded for $\mathrm{E}_{\mathrm{ac}} / \mathrm{B}$. Figure $\mathbf{S 3 2}$ shows the variation of $\mathrm{Cp}$ as function of temperature in the low temperature range and measured at different isotherms when warming the sample. Within our experimental resolution, no dielectric anomaly was detected that would correspond to the temperature of long range magnetic ordering. However, as shown in Figure 6, we do observe a positive magnetocapacitance $(\mathrm{ME}=\mathrm{Cp}(\mathrm{B}) / \mathrm{Cp}(0)-1=0.16 \%$ at $10 \mathrm{~K}$ and $7 \mathrm{~T})$. Its variation as function of temperature is reported in Figure 7. Quite interestingly, this magnetocapacitance effect persists up to relatively large temperature, around $110 \mathrm{~K}$. Two other characteristics temperatures can be observed, 50K where the magnitude of the magnetoelectric effect changes by a factor of 2.6 and $17 \mathrm{~K}$ where a smaller but quite clear anomaly can be seen. By comparing with the thermal variation of magnetic susceptibility, some similarities can be noted. The highest temperature corresponds to the departure from a pure Curie Weiss susceptibility (Figure S33) and to the appearence of short range magnetic correlations which apparently trigger the magnetoelectric effect in this compound. The two other characteristic temperatures correspond respectively to the change of dimensionality of the magnetic behaviour of the hybrid compound, from 2D to 3D short range magnetic correlations (around $50 \mathrm{~K}$ ) (unfortunately, due tot he existence of a distribution of ordering temperatures (Figure 4), it was not possible to perform an accurate dimensionality analysis of the magnetic behaviour, but the expected transition from 2D to 3D behaviour is indeed expected in this temperature range ${ }^{[105,106]}$ ), and to the occurrence of longrange magnetic ordering (around $17 \mathrm{~K}$ ). Finally, it is worth noting that the magnetic threshold field necessary for th magneto-electric effect to appear becomes zero below the magnetic ordering temperature of the compound (Figure 8) 


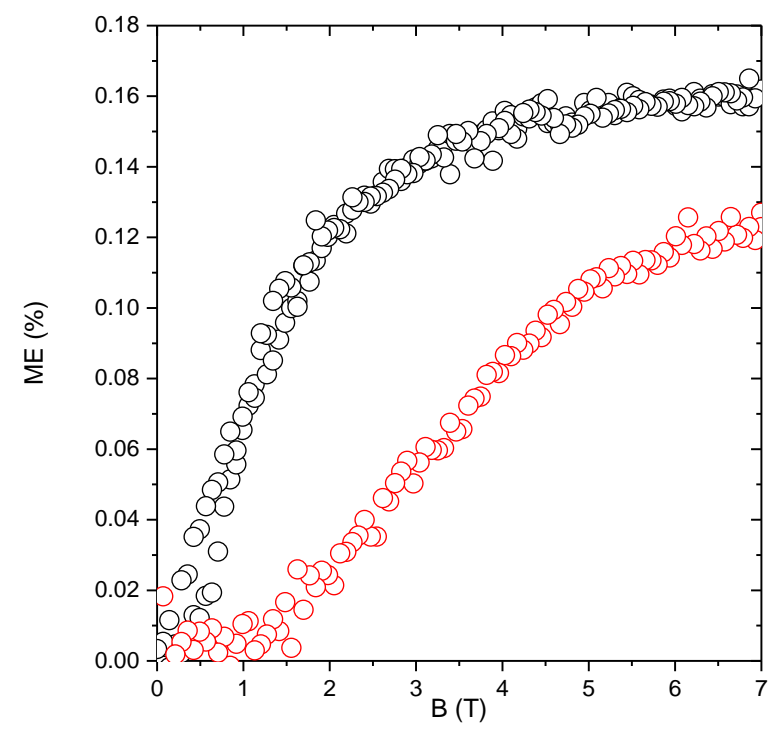

Figure 6. Relative magnetocapacitance of $\mathbf{6 c} \subset \mathbf{C o}$ as a function of the magnetic field at $10 \mathrm{~K}$ (open black circles) and $35 \mathrm{~K}$ (open red circles) (measured with field ramping up and down, $\mathrm{B} / / \mathrm{Eac})$.

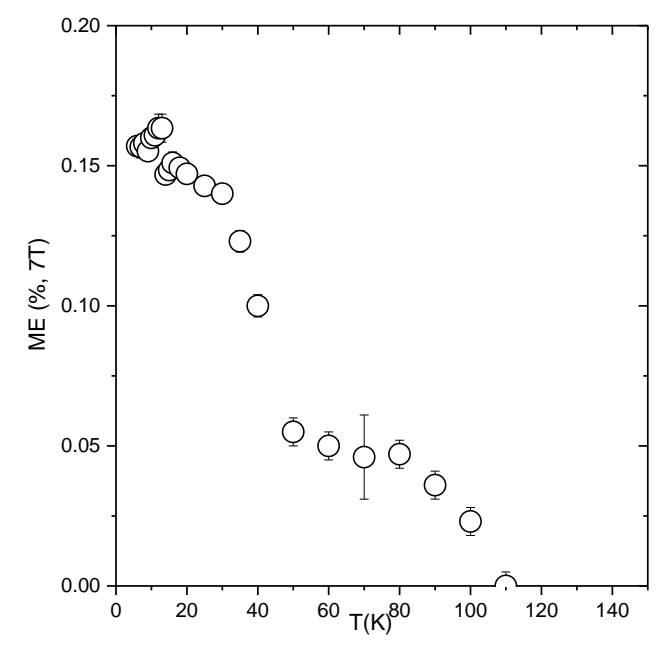

Figure 7. Relative magnetocapacitance of $\mathbf{6 c} \subset \mathrm{Co}$ at $7 \mathrm{~T}(\mathrm{~B} / / \mathrm{Eac})$ as a function of temperature. 


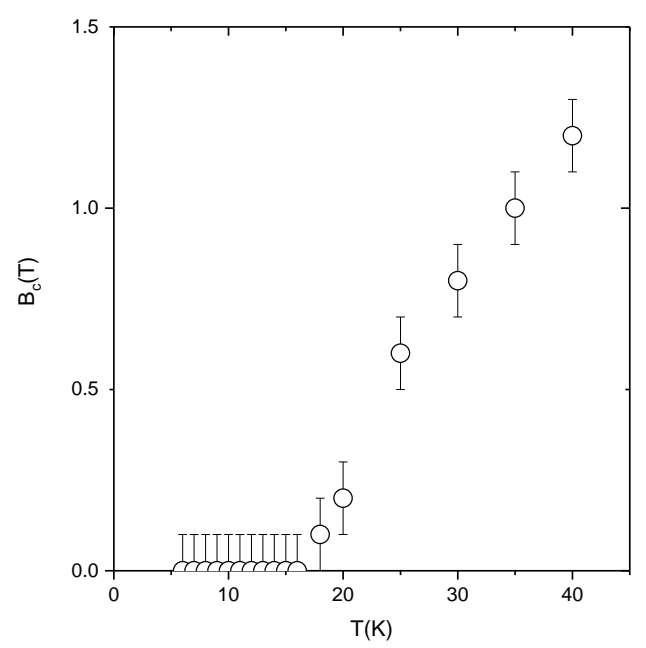

Figure 8. Magneto-electric threshold field for $\mathbf{6 c} \subset \mathbf{C o}$ as a function of temperature (B//Eac).

For the second geometry, $\mathrm{E}_{\mathrm{ac}} \perp \mathrm{B}$, we still observe a magnetocapacitance effect, but with opposite sign and a lower magnitude. This is clearly seen in Figure S34 where the magnetoelectric effects measured at the same temperature for both geometries are shown. This anisotropic effect is likely related to a preferred local orientation of microcrystalline platelets that compose the pellets. This will be studied in more details in a next future, and may give important informations on the intrinsic mechanism of spin charge coupling in this sample.

\section{6bcCo}

For this sample, the magnetoelectric properties were only measured for $\mathrm{E}_{\mathrm{ac}} \perp \mathrm{B}$ configuration. We measure a small negative magnetocapacitance with the same order of magnitude than for 6c $\subset$ Co, which goes to zero at a temperature close to $60 \mathrm{~K}$ (Figure S35 and S36). Here, a dielectric anomaly is evidenced at the temperature where the magnetocapacitance appears. This anomaly is observed both when sweeping the temperature and after a long time stabilization at different isotherms (Figure S37). Then, a clear magnetoelectric coupling can 
be inferred, emerging at a temperature $\mathrm{T} \lesssim 60 \mathrm{~K}$. Again, this temperature is much larger than the temperature where the magnetic long range ordering takes place $\left(\mathrm{T}_{\mathrm{N}} \approx 11 \mathrm{~K}\right)$ and rather corresponds to the temperature where short range magnetic correlations occur.

It is worth noting that the emergence of magnetoelectricity in a paramagnetic state has been only rarely reported. A first example was the piezzoelectric paramagnet $\mathrm{NiSO}_{4} \cdot 6 \mathrm{H}_{2} \mathrm{O}$ where a small magnetoelectric effect was reported and principally attributed to crystal field splitting. ${ }^{[107]}$ More recently, a nonlinear magnetoelectric effect was shown to survive in the praramagnetic regime in $\mathrm{CsCuCl}_{3} .{ }^{[108]}$ The coincidence of magnetoelectric effect starting precisely at the temperature where short-range magnetic correlation can be deduced from the Curie Weiss susceptibility is all the more scarce. Tot he best of our knowledge it has only been reported for the Metal Organic Framework $\left[\left(\mathrm{CH}_{3}\right)_{2} \mathrm{NH}_{2}\right] \mathrm{Mn}(\mathrm{HCOO})_{3} \cdot{ }^{[109]}$ In general, such a change in absence of long range magnetic ordering implies a local spin lattice interaction where elastic energy plays a significant role. This indicates that a magnetoelasticdriven interaction is likely the driving force of the measured magnetoelectric effects.

\section{Conclusion}

In the present work we demonstrated that mono and diphosphonic acids bearing fluorene motif can be effectively grafted into copper- and cobalt-based hydroxides to create novel hybrid Layered Simple Hydroxides. We addressed the detailed assessment of the internal structure and bonding nature for both classes of transition metals via a thorough set of characterization techniques.

For the copper-based LSH class, for which more elusive experimental findings are found, we employed first-principles molecular dynamics simulations to disentangle the interlayer arrangement of both mono and diphosphonic acids as well as the stabilizing role of the $\mathrm{H}$ bonding network promoted within the surrounding of the phosphonate groups. In particular, 
taking advantage of the Wannier centers analysis we elucidated the complex interplay between the electric field induced by local electron density fluctuations and the interlayer inhomogenous H-bonding network.

For the cobalt-based class in addition to quantify its ferromagnetic behaviour, with ordering temperatures around $15 \mathrm{~K}$, we reveal a clear magneto electric effect: application of a magnetic field to the material significantly modifies its capacitance. This effect appears above a threshold magnetic field, which is null below the magnetic ordering temperature, and it persists in the paramagnetic regime, which is very rare.

These finding pave a novel way to fill the critical need for a deeper understanding of the influence of the organic and inorganic subcomponent interactions for innovative magnetoelectric hybrid compounds with potential ferroelectric properties.

\section{Experimental Section}

General: All organic compounds were fully characterized by ${ }^{1} \mathrm{H}(500.13,400.133$ or 300.135 $\mathrm{MHz})$ and ${ }^{13} \mathrm{C}(125.773$ or $75.480 \mathrm{MHz})$ and ${ }^{31} \mathrm{P}(162$ or $121.5 \mathrm{MHz}) \mathrm{NMR}$ spectroscopy (Bruker AC 300, Avance DRX 400 and Avance DRX 500 spectrometers). Coupling constants $\mathrm{J}$ are given in hertz. The following abbreviations were used: $\mathrm{s}$ for singlet, $\mathrm{d}$ doublet, $\mathrm{t}$ triplet, $\mathrm{q}$ quadruplet, qt quintuplet, sx sextuplet, $\mathrm{m}$ for multiplet and dt for doublet of triplets. The ESI mass spectra were recorded with a Shimadzu LCMS-2020instrument with samples in MeOH or in $\mathrm{CH}_{3} \mathrm{CN}$. The IR spectra of the organic compounds were recorded with a Nicolet Nexus FTIR spectrometer working in the transmittance mode in the $\tilde{v}=200-4000 \mathrm{~cm}^{-1}$ range. Powder X-ray diffraction (XRD) patterns were collected with a Bruker D8 diffractometer $(\mathrm{Cu}$ $\mathrm{K} \alpha 1=0.1540598 \mathrm{~nm}$ ) equipped with a LynxEye detector discriminating in energy. FT-IR spectra of the hybrid compounds were collected in ATR mode on a SpectrumII spectrometer (PerkinElmer). UV/Vis/NIR studies were performed with a Perkin-Elmer Lambda 950 spectrometer (spectra recorded in the reflection mode, using a $150 \mathrm{~mm}$ integrating sphere, 
with a resolution of $2 \mathrm{~nm}$ and a mean sampling rate of $200 \mathrm{~nm} / \mathrm{min}$ ). Elemental analyses for $\mathrm{Co}, \mathrm{Cu}, \mathrm{C}, \mathrm{H}$ and $\mathrm{P}$ were performed by the Analytische Laboratorien, Lindlar, Germany. The SEM images were obtained with a JEOL 6700F microscope equipped with a field emission gun, operating at $3 \mathrm{kV}$ in the SEI mode. The magnetic studies were carried out with a SQUID magnetometer (Quantum Design MPMS3) covering the temperature and field ranges 2-300 K and $+/-7 \mathrm{~T}$, respectively. Magnetization versus field measurements at room temperature confirm the absence of ferromagnetic impurities. Data were corrected for the sample holder, and diamagnetism was estimated from Pascal constants.

The sample for magneto-dielectric measurements were prepared as pellets of typical thicknesses 200 and $140 \mu \mathrm{m}$ for $\mathbf{6 b \subset C o}$ and $\mathbf{6 c} \subset \mathbf{C o}$ respectively. Electrodes of surface $\mathrm{S}$ $\approx 0.5 \mathrm{~cm}^{2}$ were painted using silver paste Dupont 4929 which has advantages of large viscosity and of possible curing at room temperature. Special care was taken and preliminary tests were made to ensure that the paste does not diffuse and/or react with the materials. The complex impedance was measured as function of temperature and magnetic field in a PPMS (Quantum Design) using the 4282 Agilent LCR meter and a home made sample holder. The typical ac voltage was $300 \mathrm{mV}$ (linear response) and the frequency was sweeped from $20 \mathrm{~Hz}$ to $800 \mathrm{KHz}$ to analyse the complex impedance. Within resolution, the frequency response was that of a simple parallel R-C circuit in the quasi-insulating limit $(1 / \mathrm{R} \rightarrow 0$, phase angle $\theta \approx-\pi / 2)$. The capacitance was then deduced and its variation versus field and temperature extracted. The detailed synthesis of the organic molecules and of the hybrid compounds is described in Supporting Information.

\section{Theoretical methods}

First-principles molecular dynamics (FPMD) simulations have been conducted in the framework of the density functional theory (DFT) ${ }^{[110]}$ to elucidate structural and bonding 
properties of the targeted hybrid systems. In particular, we exploit the modeling framework of references $^{[88-91]}$ to carry out FPMD simulations of two representative hybrid systems: $3 \mathbf{a} \subset \mathbf{C u}$ and $\mathbf{6 a} \subset \mathbf{C u}$. We adopted the Car-Parrinello approach $(\mathrm{CPMD})^{[111]}$ and the Becke-Lee-YangParr (BLYP) functional ${ }^{[112,113]}$ to describe the exchange-correlation interactions. Valence electrons are treated explicitly, whereas norm-conserving pseudo-potentials of the Troullier and Martins type ${ }^{[114]}$ account for the core-valence interaction. For $\mathrm{Cu}$ semi-core states were included in the plane-wave (PW) expansion. ${ }^{[114]}$ The The wave functions are expanded on a PW basis set with an energy cutoff of 90 Ry and the Brillouin zone sampling of the supercell is limited to the $\Gamma$ point. Van der Waals (vdW) interactions, fundamental in our systems, were included according to the empirical formulation of Grimme. ${ }^{[115]}$ Yet, since no adjustable parameter is required, its inclusion does not affect at any stage the Kohn-Sham equations, thus preserving the first-principles character of the electronic structure calculations.

The $\mathbf{3} \mathbf{a} \subset \mathbf{C u}$ and $\mathbf{6} \mathbf{a} \subset \mathbf{C u}$ hybrid systems were initially built starting from the optimized configuration of the copper hydroxide acetate $^{[91]}$ and setting the $c$ lattice parameter to experimental values. The initial acetate groups were substituted with the 3a and $\mathbf{6 a}$ molecules in accordance with the structural formula experimentally determined and by introducing the correct amount of water molecules. In so doing, we obtained two models of 252 and 206 total atoms for the $\mathbf{3 a} \subset \mathbf{C u}$ and $\mathbf{6 a} \subset \mathbf{C u}$ systems $\left(\mathrm{Cu}_{2}(\mathrm{OH})_{3.5}\left(\mathrm{C}_{13} \mathrm{H}_{11} \mathrm{O}_{3} \mathrm{P}\right)_{0.5} \cdot 3 \mathrm{H}_{2} \mathrm{O}\right.$ and $\left.\mathrm{Cu}_{2}(\mathrm{OH})_{3.5}\left(\mathrm{C}_{13} \mathrm{H}_{10} \mathrm{O}_{6} \mathrm{P}_{2}\right)_{0.25} \cdot 3 \mathrm{H}_{2} \mathrm{O}\right)$, respectively. Energy optimization via a conjugate gradient algorithm was used to fully relax the system. Then, we performed a damped FPMD to quench the surface model at $T=0 \mathrm{~K}$. To allow the local environments of the phosphonic acids to rearrange at finite temperature, we performed FPMD simulations increasing gradually the temperature up to $50 \mathrm{~K}$ constraining the $\mathrm{Cu}$ atoms and the hydroxide groups to their equilibrium position during the initial 1 ps. The ionic temperature was controlled by NoséHoover thermostat in all our canonical (NVT) simulations. The hydroxide groups were then 
released by all constraints and the systems were equilibrated for additional 5 ps. The analysis of the interlayer structures was performed averaging the data computed along these last $5 \mathrm{ps.}$ The electronic properties of the water molecules and interlayers were analyzed by averaging over 25 uncorrelated configurations taken along the trajectory of 5 ps and computing the maximally-localized Wannier functions.

Following our former works, ${ }^{[88-91]}$ to explore ground states differing in the local spin densities, we assigned different initial random values to the fictitious electronic degree of freedom. Specifically, we performed several initial randomizations per magnetization state. Further details about the procedure employed can be found in reference ${ }^{[91]}$. This procedure allows for the exploration of multiple-minima landscapes resulting from the existence of different spin configurations for a given value of the imposed multiplicity. Each multiplicity corresponds to a total value $S$ for the projection along the $z$-direction of the total spin. In this way one obtains different local intralayer spin configurations and associated values $\Sigma(\Sigma=0$ or $\Sigma \neq 0)$ corresponding to an identical multiplicity for the whole system. Herein, we consider both limiting cases of total spin multiplicity $2 S+1$ corresponding to values equal to $1(S=0)$ and $33(S=16)$. The structure and the electronic properties discussed in this paper refer to the ground antiferromagnetic states $(S=0)$ for both $\mathbf{3 a} \subset \mathbf{C u}$ and $\mathbf{6} \mathbf{a} \subset \mathbf{C u}$ systems as being the most energetically stable states in the simulated conditions.

\section{Supporting Information}

Supporting Information is available from the author.

\section{Acknowledgements}

The authors thank the CNRS, the Universite de Strasbourg, the ENSICAEN, the Université Européenne de Bretagne, the Agence Nationale de la Recherche (contract N ${ }^{\circ}$ ANR-14-CE070004-01 (HYMN)) and the Labex NIE (ANR-11-LABX-0058_NIE within the Investissement 
d'Avenir program ANR-10-IDEX-0002-02) for financial support. We acknowledge computational facilities provided by HPC Equipe@MESO and the Idex program "Investissements d'Avenir" (2015-2016) of the University of Strasbourg.

\# These authors contributed equally to this work.

\section{References}

[1] R. Ramesh, Nature 2009, 461, 1218.

[2] G. Rogez, N. Viart, M. Drillon, Angew. Chem. Int. Ed. 2010, 49, 1921.

[3] H.-R. Wen, Y.-Z. Tang, C.-M. Liu, J.-L. Chen, C.-L. Yu, Inorg. Chem. 2009, 48, 10177.

[4] S. Ohkoshi, H. Tokoro, T. Matsuda, H. Takahashi, H. Irie, K. Hashimoto, Angew. Chem. Int. Ed. 2007, 46, 3238.

[5] P. Jain, V. Ramachandran, R. J. Clark, H. D. Zhou, B. H. Toby, N. S. Dalal, H. W. Kroto, A. K. Cheetham, J. Am. Chem. Soc. 2009, 131, 13625.

[6] P. Jain, N. S. Dalal, B. H. Toby, H. W. Kroto, A. K. Cheetham, J. Am. Chem. Soc. 2008, 130, 10450.

[7] X.-Y. Wang, L. Gan, S.-W. Zhang, S. Gao, Inorg. Chem. 2004, 43, 4615.

[8] X.-Y. Wang, Z.-M. Wang, S. Gao, Chem. Commun. 2008, 281.

[9] M. Mączka, A. Gągor, M. Ptak, W. Paraguassu, T. A. da Silva, A. Sieradzki, A. Pikul, Chem. Mater. 2017, 29, 2264.

[10] A. Stroppa, P. Jain, P. Barone, M. Marsman, J. M. Perez-Mato, A. K. Cheetham, H. W. Kroto, S. Picozzi, Angew. Chem. Int. Ed. 2011, 50, 5847.

[11] E. Pardo, C. Train, H. Liu, L.-M. Chamoreau, B. Dkhil, K. Boubekeur, F. Lloret, K. Nakatani, H. Tokoro, S. Ohkoshi, M. Verdaguer, Angew. Chem. Int. Ed. 2012, 51, 8356.

[12] D. B. Mitzi, In Progress in Inorganic Chemistry; Karlin, K. D., Ed.; John Wiley \& Sons, Inc., 1999; pp. 1-121.

[13] D. B. Mitzi, In Functional Hybrid Materials; Romero, P.-G.; Sanchez, C., Eds.; Wiley-VCH, 2004; pp. 347-390.

[14] D. B. Mitzi, J. Chem. Soc. Dalton Trans. 2001, 1.

[15] A. O. Polyakov, A. H. Arkenbout, J. Baas, G. R. Blake, A. Meetsma, A. Caretta, P. H. M. van Loosdrecht, T. T. M. Palstra, Chem. Mater. 2012, 24, 133.

[16] B. Kundys, A. Lappas, M. Viret, V. Kapustianyk, V. Rudyk, S. Semak, C. Simon, I. Bakaimi, Phys. Rev. B 2010, 81, 224434.

[17] R. Ramesh, N. A. Spaldin, Nat. Mater. 2007, 6, 21.

[18] M. Trassin, J. D. Clarkson, S. R. Bowden, J. Liu, J. T. Heron, R. J. Paull, E. Arenholz, D. T. Pierce, J. Unguris, Phys. Rev. B 2013, 87, 134426.

[19] V. Gorige, R. Kati, D. H. Yoon, P. S. A. Kumar, J. Phys. Appl. Phys. 2016, 49, 405001.

[20] M. Clemente-León, E. Coronado, C. Martí-Gastaldo, F. M. Romero, Chem. Soc. Rev. 2011, 40, 473.

[21] C. Train, M. Gruselle, M. Verdaguer, Chem. Soc. Rev. 2011, 40, 3297.

[22] R. Clément, A. Léaustic, In Magnetism: Molecules to Materials II. Molecule-based Materials; Miller, J. S.; Drillon, M., Eds.; Wiley-VCH: Weinheim, 2001.

[23] E. Coronado, C. Martí-Gastaldo, E. Navarro-Moratalla, A. Ribera, S. J. Blundell, P. J. Baker, Nat. Chem. 2010, 2, 1031. 
[24] C. Train, R. Gheorghe, V. Krstic, L.-M. Chamoreau, N. S. Ovanesyan, G. L. J. A. Rikken, M. Gruselle, M. Verdaguer, Nat. Mater. 2008, 7, 729.

[25] P. G. Lacroix, I. Malfant, S. Bénard, P. Yu, E. Rivière, K. Nakatani, Chem. Mater. 2001, 13, 441.

[26] G. Rogez, C. Massobrio, P. Rabu, M. Drillon, Chem. Soc. Rev. 2011, 40, 1031.

[27] É. Delahaye, S. Eyele-Mezui, J.-F. Bardeau, C. Leuvrey, L. Mager, P. Rabu, G. Rogez, J. Mater. Chem. 2009, 19, 6106.

[28] É. Delahaye, S. Eyele-Mezui, M. Diop, C. Leuvrey, P. Rabu, G. Rogez, Dalton Trans. 2010, 39, 10577.

[29] S. Eyele-Mezui, E. Delahaye, G. Rogez, P. Rabu, Eur. J. Inorg. Chem. 2012, 5225.

[30] R. Bourzami, S. Eyele-Mezui, E. Delahaye, M. Drillon, P. Rabu, N. Parizel, S. Choua, P. Turek, G. Rogez, Inorg. Chem. 2014, 53, 1184.

[31] O. Palamarciuc, E. Delahaye, P. Rabu, G. Rogez, New J. Chem. 2014, 38, 2016.

[32] V. Prévot, C. Forano, J. P. Besse, Appl. Clay Sci. 2001, 18, 3.

[33] H. Nijs, A. Clearfield, E. F. Vansant, Microporous Mesoporous Mater. 1998, 23, 97.

[34] Metal Phosphonate Chemistry: From Synthesis to Applications; Clearfield, A.; Demadis, K. D., Eds.; RSC Publishing: Cambridge, UK, 2011.

[35] B. S. Gelfand, R. P. S. Huynh, R. K. Mah, G. K. H. Shimizu, Angew. Chem. Int. Ed. 2016, 55, 14614.

[36] M. Taddei, F. Costantino, F. Marmottini, A. Comotti, P. Sozzani, R. Vivani, Chem. Commun. 2014, 50, 14831.

[37] S. Pili, S. P. Argent, C. G. Morris, P. Rought, V. García-Sakai, I. P. Silverwood, T. L. Easun, M. Li, M. R. Warren, C. A. Murray, C. C. Tang, S. Yang, M. Schröder, J. Am. Chem. Soc. 2016, 138, 6352.

[38] J. M. Taylor, R. K. Mah, I. L. Moudrakovski, C. I. Ratcliffe, R. Vaidhyanathan, G. K. H. Shimizu, J. Am. Chem. Soc. 2010, 132, 14055.

[39] S. Chausson, J.-M. Rueff, M. B. Lepetit, O. Perez, R. Retoux, C. Simon, L. Le Pluart, P.-A. Jaffrès, Eur. J. Inorg. Chem. 2012, 2012, 2193.

[40] C. Bloyet, M. Roger, J.-M. Rueff, B. Raveau, J.-F. Lohier, G. Rogez, P.-A. Jaffrès, Eur. J. Inorg. Chem. 2016, 2016, 4643.

[41] J.-M. Rueff, N. Barrier, S. Boudin, V. Dorcet, V. Caignaert, P. Boullay, G. B. Hix, P.-A. Jaffrès, Dalton Trans. 2009, 10614.

[42] B. Mutelet, S. Boudin, O. Pérez, J. M. Rueff, C. Labbé, P. A. Jaffrès, Dalton Trans. 2014, 44, 1186.

[43] M. Berchel, T. L. Gall, C. Denis, S. L. Hir, F. Quentel, C. Elléouet, T. Montier, J.-M. Rueff, J.-Y. Salaün, J.-P. Haelters, G. B. Hix, P. Lehn, P.-A. Jaffrès, New J. Chem. 2011, 35, 1000.

[44] J.-M. Rueff, V. Caignaert, S. Chausson, A. Leclaire, C. Simon, O. Perez, L. Le Pluart, P.-A. Jaffrès, Eur. J. Inorg. Chem. 2008, 2008, 4117.

[45] J.-M. Rueff, O. Perez, V. Caignaert, G. Hix, M. Berchel, F. Quentel, P.-A. Jaffrès, Inorg. Chem. 2015, 54, 2152.

[46] J.-M. Rueff, O. Perez, A. Leclaire, H. Couthon-Gourvès, P.-A. Jaffrès, Eur. J. Inorg. Chem. 2009, 2009, 4870.

[47] J.-M. Rueff, O. Perez, A. Pautrat, N. Barrier, G. B. Hix, S. Hernot, H. Couthon-Gourvès, P.-A. Jaffrès, Inorg. Chem. 2012, 51, 10251.

[48] J.-M. Rueff, V. Caignaert, A. Leclaire, C. Simon, J.-P. Haelters, P.-A. Jaffrès, CrystEngComm 2009, 11, 556.

[49] N. Hugot, M. Roger, J.-M. Rueff, J. Cardin, O. Perez, V. Caignaert, B. Raveau, G. Rogez, P.A. Jaffrès, Eur. J. Inorg. Chem. 2016, 2016, 266.

[50] C. Bloyet, J.-M. Rueff, V. Caignaert, J.-F. Lohier, J. Cardin, P.-A. Jaffrès, B. Raveau, Z. Für Anorg. Allg. Chem. 2017, 643, 250. 
[51] G. B. Hix, V. Caignaert, J.-M. Rueff, L. Le Pluart, J. E. Warren, P.-A. Jaffrès, Cryst. Growth Des. 2007, 7, 208.

[52] T. Coradin, R. Clément, P. G. Lacroix, K. Nakatani, Chem. Mater. 1996, 8, 2153.

[53] P. G. Lacroix, R. Clément, K. Nakatani, J. Zyss, I. Ledoux, Science 1994, 263, 658.

[54] J. L. Colon, C. Y. Yang, A. Clearfield, C. R. Martin, J. Phys. Chem. 1988, 92, 5777.

[55] J. L. Colon, C. Y. Yang, A. Clearfield, C. R. Martin, J. Phys. Chem. 1990, 94, 874.

[56] Q. Wang, D. Yu, Y. Wang, J. Sun, J. Shen, Langmuir 2008, 24, 11684.

[57] G. Huang, S. Ma, X. Zhao, X. Yang, K. Ooi, Chem. Commun. 2009, 331.

[58] A. Shimada, Y. Yoneyama, S. Tahara, P. H. Mutin, Y. Sugahara, Chem. Mater. 2009, 21, 4155.

[59] S. Akbarian-Tefaghi, E. Teixeira Veiga, G. Amand, J. B. Wiley, Inorg. Chem. 2016, 55, 1604.

[60] Y. Wang, E. Delahaye, C. Leuvrey, F. Leroux, P. Rabu, G. Rogez, Inorg. Chem. 2016, 55, 4039.

[61] V. Laget, S. Rouba, P. Rabu, C. Hornick, M. Drillon, J Magn Magn Mater 1996, 154, L7.

[62] S. Švarcová, M. Klementová, P. Bezdička, W. Łasocha, M. Dušek, D. Hradil, Cryst. Res. Technol. 2011, 46, 1051.

[63] V. Laget, Matériaux magnétiques hybrides : Influence d'espaceurs organiques et de radicaux dans des sels basiques lamellaires de cuivre et de cobalt. Ph-D., Université Louis Pasteur: Strasbourg, France, 1998.

[64] M. Louër, D. Louër, D. Grandjean, Acta Crystallogr. Sect. B 1973, 29, 1696.

[65] M. Kurmoo, Philos. Trans. R. Soc. Lond. Math. Phys. Eng. Sci. 1999, 357, 3041.

[66] J. R. Neilson, J. A. Kurzman, R. Seshadri, D. E. Morse, Chem. - Eur. J. 2010, 16, 9998.

[67] J. R. Neilson, B. Schwenzer, R. Seshadri, D. E. Morse, Inorg. Chem. 2009, 48, 11017.

[68] V. Laget, C. Hornick, P. Rabu, M. Drillon, J. Mater. Chem. 1999, 9, 169.

[69] S. Si, A. Taubert, A. Mantion, G. Rogez, P. Rabu, Chem. Sci. 2012, 3, 1945.

[70] K. D. Demadis, S. D. Katarachia, Phosphorus Sulfur Silicon Relat. Elem. 2004, 179, 627.

[71] G. Guerrero, P. H. Mutin, A. Vioux, Chem. Mater. 2001, 13, 4367.

[72] C. S. Kim, R. J. Lad, C. P. Tripp, Sens. Actuators B Chem. 2001, 76, 442.

[73] C. Dendrinou-Samara, G. Tsotsou, L. V. Ekateriniadou, A. H. Kortsaris, C. P. Raptopoulou, A. Terzis, D. A. Kyriakidis, D. P. Kessissoglou, J. Inorg. Biochem. 1998, 71, 171.

[74] V. Robert, G. Lemercier, J. Am. Chem. Soc. 2006, 128, 1183.

[75] S.-H. Park, C. H. Lee, C. E. Lee, H.-C. Ri, S. Y. Shim, Mater. Res. Bull. 2002, 37, 1773.

[76] S.-H. Park, C. E. Lee, J. Phys. Chem. B 2005, 109, 1118.

[77] C. Bauer, P. Jacques, A. Kalt, Chem. Phys. Lett. 1999, 307, 397.

[78] M. Kurmoo, P. Day, A. Derory, C. Estournès, R. Poinsot, M. J. Stead, C. J. Kepert, J. Solid State Chem. 1999, 145, 452.

[79] G. R. Williams, D. O'Hare, Solid State Sci. 2006, 8, 971.

[80] R. Luschtinetz, G. Seifert, E. Jaehne, H.-J. P. Adler, Macromol. Symp. 2007, 254, 248.

[81] S. Yagyu, M. Yoshitake, N. Tsud, T. Chikyow, Appl. Surf. Sci. 2009, 256, 1140.

[82] S. Shori, P. J. Pellechia, H.-C. zur Loye, H. J. Ploehn, J. Colloid Interface Sci. 2015, 437, 97.

[83] A. Bree, R. Zwarich, J. Chem. Phys. 1969, 51, 912.

[84] S. Y. Lee, B. H. Boo, J. Phys. Chem. 1996, 100, 8782.

[85] A. B. P. Lever, Inorganic Electronic Spectroscopy, 2nd Edition; Elsevier: Amsterdam, 1984.

[86] A. Demessence, G. Rogez, P. Rabu, Chem. Mater. 2006, 18, 3005.

[87] A. Demessence, A. Yassar, G. Rogez, L. Miozzo, S. D. Brion, P. Rabu, J. Mater. Chem. 2010, $20,9401$.

[88] F. Yang, M. Boero, C. Massobrio, J. Phys. Chem. C 2010, 114, 20213.

[89] F. Yang, M. Boero, P. Rabu, C. Massobrio, Comptes Rendus Chim. 2012, 15, 202.

[90] F. Yang, C. Massobrio, M. Boero, J. Phys. Chem. C 2014, 118, 18700.

[91] Z. Chaker, G. Ori, M. Boero, C. Massobrio, Beilstein J. Nanotechnol. 2017, 8, 857.

[92] M. Boero, K. Terakura, T. Ikeshoji, C. C. Liew, M. Parrinello, Phys. Rev. Lett. 2000, 85, 3245. 
[93] M. Sharma, R. Resta, R. Car, Phys. Rev. Lett. 2005, 95, 187401.

[94] G. Ori, C. Massobrio, A. Bouzid, M. Boero, B. Coasne, Phys. Rev. B 2014, 90, 045423.

[95] A. Bouzid, S. Le Roux, G. Ori, M. Boero, C. Massobrio, J. Chem. Phys. 2015, 143, 034504.

[96] M. Ceriotti, J. Cuny, M. Parrinello, D. E. Manolopoulos, Proc. Natl. Acad. Sci. 2013, 110, 15591.

[97] R. Scipioni, D. A. Schmidt, M. Boero, J. Chem. Phys. 2009, 130, 024502.

[98] R. L. Carlin, Magnetochemistry; Springer-Verlag: Berlin, 1986.

[99] O. Kahn, Molecular Magnetism; VCH Publishers: New-York, 1993.

[100] J. R. Neilson, D. E. Morse, B. C. Melot, D. P. Shoemaker, J. A. Kurzman, R. Seshadri, Phys. Rev. B 2011, 83.

[101] M. Drillon, P. Panissod, J. Magn. Magn. Mater. 1998, 188, 93.

[102] F. Bellouard, M. Clemente-León, E. Coronado, J. R. Galán-Mascarós, C. J. Gómez-

García, F. Romero, K. R. Dunbar, Eur. J. Inorg. Chem. 2002, 2002, 1603.

[103] E. Coronado, J. R. Galán-Mascarós, C. J. Gómez-García, V. Laukhin, Nature 2000, $408,447$.

[104] P. Rabu, S. Angelov, P. Legoll, M. Belaiche, M. Drillon, Inorg. Chem. 1993, 32, 2463.

[105] J. Souletie, P. Rabu, M. Drillon, In Magnetism: Molecules to Materials V; Miller, J.

S.; Drillon, M., Eds.; Wiley-VCH: Weinheim, 2005.

[106] P. Rabu, J. M. Rueff, Z. L. Huang, S. Angelov, J. Souletie, M. Drillon, Polyhedron 2001, 20, 1677.

[107] S. L. Hou, N. Bloembergen, Phys. Rev. 1965, 138, A1218.

[108] A. I. Kharkovskiy, Y. V. Shaldin, V. I. Nizhankovskii, J. Appl. Phys. 2016, 119, 014101.

[109] W. Wang, L.-Q. Yan, J.-Z. Cong, Y.-L. Zhao, F. Wang, S.-P. Shen, T. Zou, D. Zhang, S.-G. Wang, X.-F. Han, Y. Sun, Sci. Rep. 2013, 3, srep02024.

[110] W. Kohn, L. J. Sham, Phys. Rev. 1965, 140, A1133.

[111] R. Car, M. Parrinello, Phys. Rev. Lett. 1985, 55, 2471.

[112] A. D. Becke, Phys. Rev. A 1988, 38, 3098.

[113] C. Lee, W. Yang, R. G. Parr, Phys. Rev. B 1988, 37, 785.

[114] N. Troullier, J. L. Martins, Phys. Rev. B 1991, 43, 1993.

[115] S. Grimme, J. Comput. Chem. 2006, 27, 1787. 